Nat Rev Mol Cell Biol. 2014 February ; 15(2): 108-121. doi:10.1038/nrm3742.

\title{
A day in the life of the spliceosome
}

\author{
A. Gregory Matera ${ }^{1,2,4,5}$ and Zefeng Wang ${ }^{3,4}$ \\ ${ }^{1}$ Department of Biology, University of North Carolina, Chapel Hill, NC 27599 \\ 2Department of Genetics, University of North Carolina, Chapel Hill, NC 27599 \\ ${ }^{3}$ Department of Pharmacology, University of North Carolina, Chapel Hill, NC 27599 \\ ${ }^{4}$ Lineberger Comprehensive Cancer Center, University of North Carolina, Chapel Hill, NC 27599 \\ ${ }^{5}$ Integrative Program for Biological and Genome Sciences, University of North Carolina, Chapel \\ Hill, NC 27599
}

\section{Abstract}

One of the most amazing findings in molecular biology was the discovery that eukaryotic genes are discontinuous, interrupted by stretches of non-coding sequence. The subsequent realization that the intervening regions are removed from pre-mRNA transcripts via the activity of a common set of small nuclear RNAs (snRNAs), which assemble together with associated proteins into a spliceosome, was equally surprising. How do cells orchestrate the assembly of this molecular machine? And how does the spliceosome accurately recognize exons and introns to carry out the splicing reaction? Insights into these questions have been gained by studying the life cycle of spliceosomal snRNAs from their transcription, nuclear export and reimport, all the way through to their dynamic assembly into the spliceosome. This assembly process can also affect the regulation of alternative splicing and has implications for human disease.

Most genes in higher eukaryotes are transcribed as pre-mRNAs that contain intervening sequences (introns) as well as expressed sequences (exons). Discovered in the late 1970s, introns are now known to be removed during the process of pre-mRNA splicing, which joins exons together to produce mature mRNAs ${ }^{1,2}$. Because most human genes contain multiple introns, splicing is a crucial step in gene expression. Although the splicing reaction is chemically simple, what occurs inside a cell is much more complicated: splicing is catalysed in two distinct steps by a dynamic ribonucleoprotein (RNP) machine called the spliceosome ${ }^{3}$, requiring hydrolysis of a large quantity of $\mathrm{ATP}^{4}$. This increased complexity is thought to ensure that splicing is accurate and regulated.

The spliceosome is composed of five different RNP subunits, along with a host of associated protein co-factors ${ }^{4,5}$. To distinguish them from other cellular RNPs such as the ribosomal subunits, the spliceosomal subunits were termed small nuclear RNPs (snRNPs). As with ribosome assembly, the biogenesis of spliceosomal snRNPs is a multi-step process that takes place in distinct subcellular compartments. A common principle in the biogenesis of snRNPs 
is the assembly of stable, but inactive, pre-RNPs that require maturation at locations that are distinct from their sites of function. Assembly of functional complexes and delivery to their final destinations are often regulated by progression through a series of intermediate complexes and subcellular locales.

In this Review, we discuss the key steps in the life cycle of spliceosomal snRNPs. We focus on how snRNAs are synthesized and assembled with proteins into RNPs, and furthermore, how the snRNPs are assembled into the spliceosome. Finally, we highlight our current knowledge of regulatory proteins and how they affect snRNP function. We draw upon recent insights from molecular, genetic, genomic and ultrastructural studies to illustrate how these factors ultimately dictate splice site choice.

\section{Biogenesis of spliceosomal RNPs}

Small nuclear RNAs are a group of abundant, non-coding, non-polyadenylated transcripts that carry out their functions in the nucleoplasm. On the basis of common sequence features and protein cofactors, they can be subdivided into two major classes: Sm and Sm-like snRNAs ${ }^{6}$. Below, we focus on the biogenesis and processing of the major and minor Sm class spliceosomal snRNAs: U1, U2, U4, U4atac, U5, U11 and U12. Biogenesis of the Smlike snRNAs (U6 and U6atac) is distinct from that of Sm class RNAs ${ }^{6}$ and will not be discussed in detail here.

\section{Transcription and processing of small nuclear RNAs}

In metazoans, transcription and processing of snRNAs are coupled by a cellular system that is parallel to, but distinct from, the one that generates mRNAs. Indeed, snRNA genes share many common features with protein-coding genes, including the relative positioning of elements that control transcription and RNA processing (Fig. 1). Sm class snRNAs are transcribed from highly specialized RNA polymerase II (pol II) promoters that contain proximal and distal sequence elements similar to the TATA box and enhancer sequences, respectively, of protein-coding genes. In addition to the general transcription factors (GTFs: TFIIA, TFIIB, TFIIE and TFIIF), initiation of snRNA transcription requires binding of a pentameric factor called the snRNA-activating protein complex (SNAPc) ${ }^{7}, 8$. Promoterswapping experiments have shown that factors required for the accurate recognition of snRNA $3^{\prime}$ processing signals must load onto the polymerase in a promoter-proximal fashion. ${ }^{9}$ Specific post-translational modifications of the C-terminal domain (CTD) of the pol II large subunit are important for loading of these processing factors and for accurate processing ${ }^{10,11}$. Similarly to other pol II transcripts, capping of the $5^{\prime}$ end of an snRNA and cleavage of its $3^{\prime}$ end are thought to occur co-transcriptionally (Fig. 1).

Maturation of the snRNA $3^{\prime}$ end requires a large, multi-subunit factor called the Integrator complex ${ }^{12,13}$, which recognizes a downstream processing signal (called the $3^{\prime}$-box) and endonucleolytically cleaves the nascent transcript as it emerges from the polymerase (Fig. 1). Whether this cleavage occurs prior to, or concomitant with, arrival of pol II at the downstream terminator sequence is not known. Interestingly, Integrator Subunit 11 (IntS11) and IntS9 share significant sequence similarity to components of the mRNA $3^{\prime}$ end processing machinery, CPSF73 and CPSF100, respectively ${ }^{12,14,15}$. But beyond these two 
subunits, the additional Integrator complex proteins bear little similarity to those involved in mRNA cleavage and polyadenylation ${ }^{13}, 16$. Notably, the Cdk8-CyclinC heterodimer shows snRNA $3^{\prime}$ processing activity in a reporter assay and physically associates with the Integrator complex. ${ }^{13}$ Although the kinase activity of Cdk8-CyclinC was also essential for processing, whether it phosphorylates Integrator subunits and/or the pol II CTD remains unclear $^{13}$. Thus, the precise mechanism by which metazoan pol II snRNA gene transcription is terminated remains mysterious. What is clear is that $3^{\prime}$ end processing of Sm class snRNAs requires three important features: an snRNA-specific promoter, a cis-acting $3^{\prime}$-box element located downstream of the cleavage site and an assortment of trans-acting factors that load onto the pol II CTD (Fig. 1).

\section{Nuclear export, Cajal bodies and RNP quality control}

Sm class snRNPs primarily function in the nucleus. However, in most species, newly synthesized snRNAs are first exported to the cytoplasm, where they undergo additional maturation steps before they are imported back into the nucleus. Notable exceptions to this rule are found in budding yeast and trypanosomes, in which RNP assembly is thought to be entirely nuclear ${ }^{17-21}$. Why cells export precursor snRNAs to the cytoplasm only to import them after their assembly into stable RNP particles is an open question. This property is not unique to snRNAs: ribosomal subunits, which function in the cytoplasm, are primarily assembled in the nucleolus ${ }^{22}$. Both types of RNP certainly undergo remodelling steps within their 'destination' compartments, but the initial stages of particle assembly take place in remote cellular locations. This arrangement provides a plausible mechanism for quality control, ensuring that partially assembled RNPs would not come into contact with their substrates.

Most types of RNA, including rRNA, tRNA, mRNA, miRNA and SRP (signal recognition particle) RNA are exported to the cytoplasm following nuclear transcription and processing. Emerging evidence points to a role for nuclear RNA-binding factors in specifying the cytoplasmic fate of an RNA ${ }^{23}$. However, the connections between RNA processing and nuclear export are not as well worked out as they are for transcription and $3^{\prime}$ end formation. Typically, specific RNA sequences and/or structures are the determinants that promote direct or indirect binding to the appropriate transport receptor (as occurs for tRNAs and rRNAs) ${ }^{24}$. Because Sm class snRNAs and mRNAs are both transcribed by pol II, they share a $5^{\prime}$ cap structure, raising the issue of how the export machinery discriminates between these two types of RNA. Solving this longstanding riddle, an elegant series of papers has shown that snRNAs are distinguished from mRNAs on the basis of their length and their association with heterogeneous nuclear RNP (hnRNP) C1-C2 proteins ${ }^{25-28}$. Pol II mRNA transcripts that are longer than $\sim 250 \mathrm{nt}$ are bound by hnRNP C1-C2 tetramers and shunted towards the NXF1-NXT1 (also known as TAP-p15) mRNA export pathway ${ }^{28}$. Transcripts shorter than this threshold are exported by a distinct set of factors that includes the cap binding complex (CBP80 and CBP20 $)^{29}$, the snRNA-specific export adaptor PHAX ${ }^{30}$, and arsenite resistance protein $2(\operatorname{Ars} 2)^{31}$. These proteins form a link between the $5^{\prime}$ cap and the export receptor, CRM1 (also known as Exportin1), which interacts with nuclear pore proteins to promote export (Fig. 2) ${ }^{32}$. Although PHAX can bind to mRNA 5' caps in vitro, it is inhibited from doing so in vivo by hnRNP C1-C2 28 . 
Several lines of evidence indicate that precursor snRNA transcripts often traffic through snRNP-rich nuclear structures known as Cajal bodies on their way out of the nucleus. First, in situ hybridization shows that pre-snRNA transcripts with long $3^{\prime}$ extensions localize to mammalian Cajal bodies ${ }^{33}$. Second, microinjection experiments in Xenopus oocyte nuclei reveal that pre-snRNAs temporarily accumulate in Cajal bodies, and that this localization decreases over time as the RNAs are exported ${ }^{34}$. Third, PHAX and CRM1 are both concentrated in Cajal bodies ${ }^{35}, 36$. Fourth, inhibition of PHAX activity interferes with snRNA export ${ }^{30}$, and either causes pre-snRNAs to accumulate within frog oocyte Cajal bodies $^{34}$ or results in dispersal of mammalian Cajal body components ${ }^{83}$. The data are most consistent with a model whereby assembly of pre-export complexes is facilitated within Cajal bodies, followed by nuclear export upon docking to CRM1. The model further invokes a function for Cajal bodies in nuclear RNP remodelling ${ }^{37}$ and sorting ${ }^{23}$, as outlined below.

\section{Cytoplasmic RNP assembly and the SMN complex}

After the pre-snRNA translocates to the cytoplasm, dissociation of the export complex (Fig. 2 ) is triggered by dephosphorylation of PHAX ${ }^{38}$. The survival motor neuron (SMN) protein complex, which includes SMN and several tightly associated proteins, collectively called Gemins $^{39-43}$, is thought to regulate the entire cytoplasmic phase of the snRNP cycle. The SMN complex recruits the newly exported snRNAs and combines them with a set of seven Sm proteins to form a toroidal ring around an RNA binding site that is present within each of the eponymous Sm-class snRNAs (Fig. 3). The Sm proteins are delivered to the SMN complex via the activity of the PRMT5 complex, which methylates C-terminal arginine residues within $\mathrm{SmB}, \mathrm{SmD} 1$ and $\mathrm{SmD} 3^{44,45}$ and then chaperones delivery of partially assembled Sm subcomplexes ${ }^{46,47}$. Binding to the SMN complex is therefore proposed to initiate in the cytoplasm, and Gemin5 is thought to be the factor responsible for recognition of Sm site-containing RNAs ${ }^{48}$. Assembly of the Sm core not only stabilizes the snRNA by protecting it from nucleases, but is also required for the downstream RNA processing steps that culminate in nuclear import. The physiological relevance of Sm core assembly has also been emphasized by the demonstration that mutations in the gene encoding the SMN protein cause the human neuromuscular disease spinal muscular atrophy (Box 1).

\section{Box 1}

\section{Human spliceosomal diseases}

As a major regulatory step in gene expression, mis-regulation of splicing is a common feature of many human diseases. These disorders can be caused by mutations that disrupt splicing of specific genes ${ }^{175,176}$, or by a general loss of spliceosomal function, affecting many gene targets. We focus here on those that disrupt spliceosomal biogenesis and/or function.

Retinitis pigmentosa (RP) is an inherited degenerative eye disease that causes severe vision impairment and blindness. Mutations in several core spliceosomal proteins (e.g. human PRPF3, PRPF8, PRPF31, PAP1, Prp8 and Brr2) cause autosomal dominant retinitis pigmentosa ${ }^{17,177-179}$, suggesting that human retinal cells are especially sensitive to splicing defects. Mutations in the minor spliceosomal snRNA, U4atac, were recently 
shown to result in microcephalic osteodysplastic primordial dwarfism (MOPD) type $\mathrm{I}^{180}$, a rare genetic defect that causes severe growth retardation and infant death.

Spinal muscular atrophy (SMA) is a recessive neuromuscular disease caused by reduced levels of the survival motor neuron (SMN) protein. There are two SMN genes in humans, $S M N 1$ and SMN2. SMA is usually caused by homozygous deletion of SMN1. Due to a single point mutation between the two paralogues, exon 7 of $S M N 2$ is often skipped, resulting in a truncated and unstable protein product ${ }^{181}$. Consistent with the primary function of SMN in the biogenesis of spliceosomal snRNPs, complete loss of SMN function is embryonic lethal ${ }^{182}$. However it remains unclear why partial loss of SMN function causes a neuromuscular disease. Although animal models of severe SMA show differential reduction in the levels of major versus minor Sm class snRNPs, ${ }^{183}$ recent reports dispute the extent to which defects in minor intron splicing can account for SMAlike phenotypes ${ }^{184,185}$. Using an SMN point mutation that causes a mild/intermediate form of SMA in humans, Praveen et al. ${ }^{184}$ showed that the role of SMN in snRNP biogenesis can be uncoupled from the organismal viability and locomotor defects. Thus, although splicing defects are a predominant feature of severe SMA, they are detectable only relatively late in the disease course, well after the onset of neuromuscular deficits ${ }^{186}$ and a better understanding of SMA disease etiology is still required.

Chronic lymphocytic leukemia and myelodysplasia have also been associated with splicing defects ${ }^{187,} 188$. For example, core components of the U2 snRNP, such as SF3B1 and U2AF35, are frequently mutated in these cancers 187,188 . Such mutations might result in defective snRNP assembly, deregulated alternative splicing, or accumulation of unspliced mRNA, and thus may alter the expression of multiple genes ${ }^{189}$. In addition to genetic mutations, the mis-regulation of splicing factor levels has often been found to be associated with various neoplasias. Such a shift in expression level for major splicing factors in cancer may explain the extensive change of alternative splicing that is observed for thousands of genes in cancer patient samples. Therefore, targeting spliceosome function may provide a new route for cancer therapy.

Sm proteins do not bind the snRNA as a pre-formed ring. Instead, they form heterodimeric (SmD1-SmD2 and SmB-SmD3) or heterotrimeric (SmE-SmF-SmG) subcomplexes (Fig. 3). When purified in vitro, these subcomplexes spontaneously coalesce into a ring only in the presence of an appropriate RNA target ${ }^{49-51}$. However, in cell extracts, this reaction requires the whole SMN complex as well as ATP ${ }^{39}$. In vivo, the SMN complex is thus thought to provide added specificity, to avoid assembly of Sm cores onto non-target RNAs ${ }^{40,48}$ and to accelerate formation of the final product from kinetically trapped intermediates ${ }^{47}$.

One of the most surprising insights from recent studies of the SMN complex is that SMN protein is probably not the primary architect of Sm core RNP assembly. Two crystallographic studies demonstrated that Gemin2, a conserved member of the SMN complex ${ }^{52}$, binds directly to five of the seven Sm proteins (Fig. 3) and holds them in the proper 'horseshoe' orientation for subsequent snRNA binding and ring closure ${ }^{53}$. These results were not predicted from earlier in vitro binding studies of Gemin $2^{54}$ and were surprising because previous work on Sm binding had mainly focused on SMN itself ${ }^{55,56}$. 
However, given that the budding yeast genome apparently lacks SMN but contains a potential Gemin 2 orthologue ${ }^{54,57}$, the idea that Gemin2 plays a starring role in Sm core assembly is gaining considerable traction.

Precisely how SMN is involved in Sm core RNP formation is still an open question, although RNA interference analyses in metazoan cells have demonstrated it is required ${ }^{58,59}$. Moreover, SMN-Gemin2 heterodimers are sufficient for Sm core assembly activity in vitro $^{52}$. Importantly, the assembly chaperone pICln (Fig. 3) may function as an SmB-SmD3 mimic that stabilizes the pentameric Sm horseshoe structure in preparation for handoff to Gemin $2^{46,47}$. The Tudor domain of SMN contains an Sm-fold ${ }^{60}$ and is hypothesized to play a mimetic role (Fig. 3), occupying the space for SmB-SmD3 during the transition between the pICln-bound intermediate and the Gemin2-Sm pentamer structure ${ }^{46}$. The selfoligomerization activity of SMN, contained within its C-terminal YG-box domain, is also required for Sm core formation $56,59,61$. It is not yet clear how the C-terminus of SMN, which forms a YG zipper motif ${ }^{62}$, interfaces with the rest of the SMN molecule and other members of the SMN complex. These and other important questions will need to be addressed by future studies.

\section{Nuclear import and RNP remodelling}

Formation of the Sm ring protects and stabilizes the snRNA and initiates downstream RNA processing steps that culminate in nuclear import of the SMN complex (Fig. 2). As part of its overall chaperoning function, the SMN complex recruits TGS1, an RNA methyltransferase that modifies the snRNA $5^{\prime}$ end to form a 2,2,7-trimethylguanosine (TMG) structure ${ }^{43}$. The TMG cap functions as a nuclear localization signal ${ }^{63}$. Along with a subset of factors within the SMN complex, ${ }^{64}$ the Sm core itself functions as a second, parallel nuclear localization signal ${ }^{65}$. Concomitant with (or subsequent to) these $5^{\prime}$ events, the $3^{\prime}$ end of the snRNA is exonucleolytically trimmed to its mature length. Thus, SMNmediated assembly of the Sm core is required for proper cytoplasmic RNP maturation in vivo.

After import back into the nucleus, TMG cap formation triggers dissociation of TGS1 from the pre-import complex (Fig. 2); this is followed by binding of Snurportin ${ }^{66}$, the snRNPspecific import adaptor, to the hypermethylated cap structure. Snurportin interacts directly with the import receptor Importin-beta ${ }^{67}$ to promote import, although the SMN complex (or a subcomplex thereof) is also thought to accompany newly assembled snRNPs into the nucleus ${ }^{64}$. The SMN complex does not associate with nucleus-injected (that is, 'naked') RNAs; experiments in Xenopus oocyte nuclei showed that the SMN complex interacts with microinjected snRNAs only after their export to the cytoplasm ${ }^{68}$.

Once a snRNP has been imported into the nucleus, it is free to diffuse throughout the interchromatin space. SMN is thought to dissociate from the snRNP relatively soon after import, as the protein does not co-purify with mature snRNP mono-particles, spliceosomes or splicing intermediates ${ }^{69-71}$. In most cell types, the nuclear fraction of the SMN complex localizes primarily within Cajal bodies; however, SMN also accumulates in distinct nuclear substructures called Gemini bodies (or Gems) ${ }^{72}$. Cajal bodies contain a plethora of RNAs 
and their associated proteins, but components of Gems have thus far been limited to components of the SMN complex ${ }^{72,73}$.

In mammalian cells, substantial evidence points to a role for Cajal bodies in the nucleoplasmic maturation of snRNPs, following nuclear import. Newly imported Sm-class RNPs transiently accumulate in Cajal bodies prior to localizing in other nucleoplasmic subcompartments known as speckles (see below) ${ }^{74,75}$. In nuclear transport assays using digitonin-permeabilized cells, Snurportin1 and partially assembled (12S) U2 snRNPs accumulate within Cajal bodies ${ }^{76}$. Additional RNP remodelling and RNA processing steps are thought to take place in Cajal bodies, including noncoding RNA-guided covalent modification of the snRNAs ${ }^{77}$ and binding of snRNP-specific proteins ${ }^{78,} 79$. Furthermore, Cajal bodies are thought to facilitate the de novo assembly and post-splicing reassembly of U4/U6 di-snRNP and U4/U6•U5 tri-snRNP ${ }^{80-82}$. Given that Cajal body homeostasis is disrupted by depletion of a variety of snRNP biogenesis factors $59,83-85$, it is perhaps surprising that snRNP trafficking through Cajal bodies is not obligatory in mice or flies ${ }^{86-88}$ (although it seems to be essential in fish ${ }^{89}$ ). Taken together, these findings strongly suggest that Cajal bodies participate in RNP biogenesis on both the outbound and inbound legs of an snRNA's journey through the cell.

Within the nucleus, spliceosomal snRNPs and their associated co-factors (for example, SR proteins) are typically excluded from nucleoli, localizing in a punctate pattern of variably sized and irregularly shaped nuclear speckles. In fact, this speckled pattern is highly diagnostic for factors involved in pre-mRNA splicing ${ }^{75}$. Speckles are extremely dynamic nucleoplasmic domains, but contain little or no DNA and are thus thought to function as storage compartments ${ }^{90}$. Most splicing activity seems to localize to the borders between speckles and the adjacent chromatin domains ${ }^{91,92}$. Precisely how snRNPs and other splicing factors are recruited from the speckles to sites of active transcription is unclear. However, once the fully assembled snRNPs are loaded onto the pol II CTD and targeted to the site of transcription, they are then poised to carry out spliceosome assembly and pre-mRNA splicing.

\section{Spliceosomal assembly and catalysis}

Non-coding RNAs typically function as adaptors that position nucleic-acid targets adjacent to an enzymatic activity that is catalysed either by the RNAs themselves or by associated proteins $^{6}$. Consistent with this notion, spliceosomal snRNA function is driven by base pairing with short conserved motifs located at the junctions between the expressed exon sequences and the intervening introns of target mRNAs. The $5^{\prime}$ splice site (ss) of a premRNA is present at the beginning of an intron, the $3^{\prime}$ ss is located at the end of an intron, and the branch point adenosine is usually located 15-50 nucleotides upstream of the 3 'ss (Fig. 1b). In addition to the primary splicing signals located at exon-intron boundaries, splice site choice is modulated by multiple cis-acting regulatory elements throughout the pre-mRNA. As outlined below, spliceosomes are assembled onto their targets via a multistep process whereby these cis-acting elements recruit trans-acting factors that ultimately control higher order particle assembly. For more details on splicing mechanisms, readers are referred to recent reviews ${ }^{4,93}$. 


\section{Stepwise spliceosome assembly}

Although spliceosome assembly is best understood in budding yeast, the key assembly steps are well conserved in humans. For the purposes of this review, we refer to the names of yeast proteins. First, U1 snRNP recognizes the $5^{\prime}$ ss via base pairing of U1 snRNA to the mRNA, forming the early complex (complex E, Fig. 4a). In addition to base pairing, the $5^{\prime}$ ss can also be recognized by U1C, a subunit of the U1 snRNP ${ }^{94}$. This process is facilitated by the pol II CTD, which reportedly interacts directly with U1 snRNP ${ }^{95,96}$ although the functional role of this interaction is still under debate ${ }^{97}$. The interaction between the $5^{\prime}$ ss and U1 snRNP in complex E is ATP independent and fairly weak; it is stabilized by other factors such as SR proteins ${ }^{98,99}$ and the cap-binding complex ${ }^{100}$. The ${ }^{\prime}$ ss of the pre-mRNA is recognized by the U2 snRNP and associated factors, such as SF1 and U2 auxiliary factors (U2AF), which are also components of complex E.

In a subsequent ATP-dependent process catalysed by DExD/H helicases (Prp5 and Sub2), $\mathrm{U} 2$ snRNA recognizes sequences around the branch point adenosine and interacts with $\mathrm{U} 1$ snRNP to form the pre-spliceosome (complex A). Formation of an intron-spanning complex A was originally described in yeast, but more complicated assembly pathways are prevalent among higher eukaryotes. Because metazoan genes contain relatively short exons ( $\sim 50-250$ nt) that are separated by larger introns (up to $1000 \mathrm{~kb}$ ), splice sites are predominantly recognized in pairs across exons through the interaction of U1 and U2 snRNPs ${ }^{101,102}$. This process is called exon definition, and the U1-U2 snRNP complex that forms across exons is known as the exon definition complex ${ }^{103}$. In a subsequent transition step, U1 and U2 snRNPs undergo poorly understood rearrangements, forming an intron-spanning interaction known as the intron definition complex that also brings the $5^{\prime} \mathrm{ss}$, branch point and 3 'ss into close proximity ${ }^{104}$. Thus, the metazoan intron definition complex is generally considered to be equivalent to complex A in yeast, whereas the metazoan exon definition complex is similar to complex E.

Formation of the exon definition complex and the subsequent transition to the intron definition complex are intermediate stages that are crucial for regulating splicing ${ }^{105,106 .}$ After the assembly of complex A, the U4/U6 and U5 snRNPs are recruited as a preassembled tri-snRNP to form complex $\mathrm{B}$, in a reaction catalysed by the $\mathrm{DExD} / \mathrm{H}$ helicase Prp28. The resulting complex B goes through a series of compositional and conformational rearrangements to form a catalytically active complex B (complex B*). Multiple RNA helicases (Brr2, Snu114 and Prp2) are required for the activation of complex B, resulting in rearrangements that lead to the formation of U2/U6 snRNA structure that catalyses the splicing reaction ${ }^{107}$. The activation of complex B also unwinds the $\mathrm{U} 4$ and U6 snRNAs, releasing $\mathrm{U} 4$ and $\mathrm{U} 1$ from the complex ${ }^{108}$, which is thought to unmask the $5^{\prime}$ end of U6 snRNA.

Complex B* then carries out the first catalytic step of splicing, generating complex C, which contains the free exon 1 and the intron-exon 2 lariat intermediate (Fig. 4a). Complex $\mathrm{C}$ undergoes additional ATP-dependent rearrangements before carrying out the second catalytic step of splicing, dependent on Prp8, Prp16 and Slu7; this results in a postspliceosomal complex that contains the lariat intron and spliced exons. Finally, the U2, U5 and U6 snRNPs are released from the mRNP particle and recycled for additional rounds of 
splicing. As with other spliceosomal rearrangement steps, release of the spliced product from the spliceosome is catalysed by the DExD/H helicases Prp22109, 110. Disassembly of the post-catalytic spliceosome is also driven by several RNA helicases (for example, Brr2, Snu114, Prp22, Prp43) in an ATP-dependent manner ${ }^{111}$.

Single molecule analyses have provided additional insights into the process of spliceosome assembly. Fluorescence labelling has been used to visualize how individual spliceosomal subcomplexes sequentially associate with the pre-mRNA to generate functional spliceosomes ${ }^{112,113}$. Using purified components, these in vitro studies have shown that all of the major spliceosomal assembly steps are reversible ${ }^{113}$, including the catalytic splicing steps $^{114}$. This reversibility, especially that of the early steps, imply the existence of proofreading during splicing ${ }^{115}$. Commitment to splicing is thought to increase as spliceosome assembly proceeds in vitro ${ }^{113}$, consistent with the idea of a reversible stage during which partially assembled spliceosomes retain the capacity to disassemble and reassemble onto an alternative splice site. Whether or not splicing can be reversed in vivo is unclear, and additional studies will be required to address this point.

Aside from the traditional pathway of spliceosome assembly, at least two alternative models have been proposed. In one model, spliceosome assembly does not strictly depend on a premRNA substrate, and the mRNA 5'ss can be recognized by the U1 snRNP within a pentasnRNP complex containing all five snRNPs ${ }^{116,117}$. However, this penta-snRNP observed in vitro has not been supported by studies of co-transcriptional spliceosome assembly ${ }^{118}$, and a majority of the evidence indicates that initial spliceosome assembly requires the presence of a $5^{\prime}$ ss in the pre-mRNA substrate ${ }^{119}$. In an alternative model, the U4/U6 $\bullet 5$ tri-snRNP can be recruited to the exon definition complex, which then can be directly transformed into a cross-intron B-like complex without prior formation of a cross-intron complex $\mathrm{A}^{120}$.

\section{Splicing is catalysed by RNA}

The spliceosome is a dynamic complex whose components undergo multiple conformational and compositional changes during the splicing reaction. Such rearrangements occur between snRNAs, spliceosomal proteins and the pre-mRNA substrate, and are required in order to generate an activated spliceosome. The snRNAs, rather than the spliceosomal proteins, are believed to provide the catalytic activity. Previous genetic and biochemical studies have established that snRNAs and substrate pre-mRNA undergo a series of dynamic base-pairing rearrangements to achieve catalysis (reviewed in ref. ${ }^{121}$ ). More recently, it was shown that the two-step splicing reaction (i.e., the exchange of phosphodiester bonds) could be catalysed in a protein-free system by a U6/U2 snRNA complex that resembles a self-splicing ribozyme ${ }^{122,123}$. Indeed, structural analyses have provided information regarding atomic events within the catalytic core of the spliceosome during distinct stages of the splicing reaction ${ }^{124}$. Here, we provide a brief overview of how the active structure of the catalytic site is generated via RNA rearrangement (see references $4,93,121$ for more detailed reviews).

During the early stages of spliceosomal assembly, U1 snRNA base pairs with the $5^{\prime}$ ss. Meanwhile, U2 snRNA pairs with the branch point sequence, forming a short duplex that causes the branchpoint adenosine to bulge out and present its $2^{\prime}$ hydroxyl group as a nucleophile (Fig. 4b, left). Within complex A, interactions between U1 and U2 snRNPs 
bring the $5^{\prime}$ ss, the branch point and 3'ss into close proximity. Subsequently, complex A associates with the U4/U6 $\bullet 5$ tri-snRNP (Table 1). Recruitment of the tri-snRNP complex displaces the extensive base pairing between $\mathrm{U} 4$ and U6 snRNAs and leads to formation of new base pairs between U2 and U6 (Fig. 4b, middle) ${ }^{107}$. During this process, dissociation of U4 from U6 snRNA exposes the $5^{\prime}$ end of U6, which then base pairs with the $5^{\prime}$ ss, displacing U1 snRNA (Fig. 4b, right).

An extensive network of base pairs is thus formed between U6 and U2 snRNA, which juxtaposes the 5'ss and branch point adenosine for the first catalytic step of splicing. The central region of U6 snRNA forms an intramolecular stem-loop (the U6-ISL) that is key for splicing catalysis. Recruitment of the U4/U6•U5 tri-snRNP also triggers U5 snRNA interaction with exonic sequences located near the $5^{\prime}$ ss. This interaction is probably essential for anchoring exon 1 in proximity to the lariat-exon 2 in preparation for the second catalytic step of splicing (Figs. 4a and 4b). During these dynamic rearrangements, the U2/U6 complex (Fig. 4b) is thought to be the active structure that catalyses both steps of the splicing reaction. This complex shares several common structural features with the group II self-splicing introns that are found in ribozymes ${ }^{124-126}$, suggesting that spliceosomal catalysis might be mechanistically similar to that of ribozymes ${ }^{127}$.

In addition to base pairing among and between the snRNAs, divalent cations (for example, $\mathrm{Mg}^{2+}$ ) are also required for pre-mRNA splicing ${ }^{128}$. These metal ions might directly participate in the catalytic reactions and/or simply help maintain the active RNA conformation ${ }^{93}$. Using a 'metal rescue' strategy, U6 snRNA was shown to position the divalent metal ions to catalyse both steps of splicing by stabilizing the leaving groups ${ }^{127}$. The energy requirement for both catalytic steps of splicing is minimal, but a large amount of energy is devoted to RNA remodelling of the snRNAs. Spliceosomal remodelling is primarily catalysed by multiple DExD/H RNA helicase/ATPase ${ }^{129}$ and EF-G-like GTPase ${ }^{130}$ proteins.

Certain spliceosomal proteins may also improve the efficiency of splicing by stabilizing the RNA active site in vivo. For example, Prp8 is closely associated with the catalytic core of the spliceosome ${ }^{131}$ and is required for both its catalytic steps ${ }^{132}$. The Brr2 helicase unwinds U4/U6 snRNAs to allow U6 to pair with U2 and form the catalytically active structure. Moreover, the C-terminal tail of Prp8 can interact with Brr2 and inhibit this process ${ }^{133}$, suggesting that alternating interactions between snRNAs and proteins regulate spliceosomal activation. The second catalytic step of splicing is also thought to be promoted by proteins, including Prp16, Prp18 and Slu7. Notably, the ATP-dependent activity of Prp16 is sufficient to activate complex $\mathrm{C}$ for the second catalytic step of splicing ${ }^{134}$.

\section{Splicing regulation}

Most genes in higher eukaryotes undergo alternative splicing to produce multiple isoforms with distinct activities. The spliceosome is responsible for directing both constitutive and alternative splicing, and regulation of its assembly is a key control point in these processes. Alternative splicing is tightly controlled in different tissues at distinct developmental stages, and the dysregulation of splicing is associated with several human diseases (Box 1). Human 
introns are several to hundreds of kilobases in length ( $\sim 5 \mathrm{~kb}$ on average) and contain numerous 'decoy' splice sites (that is, sequences that have a similar degree of consensus matching with authentic sites). A pair of decoy splice sites often form pseudo-exons that resemble authentic exons in terms of length and splice site strength but are very rarely, if ever, spliced ${ }^{135}$. So despite these prevalent decoy sites, the splicing process occurs with high fidelity, suggesting that additional sequence features aside from core splicing signals contribute to exon-intron definition.

\section{Cis-acting elements regulate splicing}

Alternative splicing is typically controlled by numerous $c i s$-regulatory RNA elements that serve as either splicing enhancers or silencers. Based on their locations and activities, these splicing regulatory elements (SREs) have been classified as either exonic or intronic splicing enhancers and silencers (ESEs and ISEs versus ESSs and ISSs, respectively). Although the activities of SREs are often context dependent (Fig. 5a), these sequences generally function by recruiting trans-acting splicing factors that activate or suppress different steps of the splicing reaction ${ }^{136,137 .}$

How splicing factors affect splicing decisions has been a topic of extensive research. Many splicing factors are auxiliary proteins of the spliceosome and interact with its core components to regulate splicing $5,138-140$. Most known splicing factors control splicing by affecting the early and intermediate steps of spliceosomal assembly: formation of the exon definition complex and the subsequent transition to the intron-spanning complex A. A wellstudied example is the polypyrimidine-tract-binding protein, PTB, which typically inhibits splicing by binding to short polypyrimidine-rich elements in pre-mRNAs. When binding to exons, PTB can cause exon skipping by recognizing an ESS and inhibiting formation of the exon definition complex ${ }^{141}$. PTB can also inhibit splicing by affecting the transition from an exon definition complex to an intron definition complex ${ }^{106}$, and can directly interact with U1 snRNP to prevent its interaction with other spliceosomal components ${ }^{142}$ (Fig. 5a). Similarly, the splicing factor RBM5 interacts with a U2 snRNP component (U2AF65) and inhibits the transition from an exon definition to intron definition complex ${ }^{105}$. In addition, hnRNP L and hnRNP A1 induce extended contacts between U1 snRNA at the 5'ss and neighbouring exonic sequences that, in turn, inhibit stable association of U6 snRNA and subsequent spliceosomal catalysis ${ }^{143}$. In addition to the early steps of spliceosomal assembly, an alternative exon in the CD45 mRNA was found to be inhibited after ATPdependent exon recognition ${ }^{144}$, suggesting that alternative splicing can be regulated at many points along the spliceosomal assembly pathway.

The activities of SREs often depend on their relative locations within pre-mRNAs (Fig. 5b). This context dependence highlights how flexible the interactions of splicing regulatory factors with the core splicing machinery are. Given the complexities of spliceosomes, it is not surprising that the effects of splicing factors on core spliceosomal components might vary, depending on their relative positions on the pre-mRNA. For example, oligo-G tracts commonly enhance splicing from intronic locations by recruiting hnRNP $\mathrm{H}^{145}, 146$, but these same elements can inhibit splicing when located in exons ${ }^{147,} 148$ (Fig. 5b). The underlying mechanism for such activities may involve inhibition of the exon definition complex by 
hnRNP H 'across' the site of binding. Similarly, the YCAY motifs that are recognized by the Nova family of neuron-specific splicing factors can function as ESEs, ISEs or ISSs, depending on their positions relative to the regulated exon ${ }^{149}$ (Fig. 5b). SR proteins usually promote splicing when bound to exons, but they can inhibit splicing when associated with introns ${ }^{150}$. Moreover, hnRNP A1 can inhibit splicing from either exonic or intronic locations ${ }^{150}$ (Fig. 5b). Notable exceptions to these rules have also been observed. For example, the Drosophila orthologues of hnRNP A1 can enhance splicing from an intron ${ }^{151}$.

U1 snRNPs can also suppress splicing or inhibit polyadenylation by interacting with 5'sslike RNA elements. In an unbiased screen, sequences resembling $5^{\prime}$ splice sites were identified as ESSs that inhibit exon inclusion ${ }^{152}$. The binding kinetics between U1 snRNP and the 5 'ss can also affect alternative splice site choice, independent of the activities of other splicing factors ${ }^{153}$. Non-conventional functions of U1 snRNPs in preventing premature mRNA cleavage and polyadenylation are discussed in greater detail in Box 2.

\section{Box 2}

\section{The unusual activities of U1 snRNP}

In addition to its function in the spliceosome, U1 snRNP has additional roles in RNA processing. As a core component of the spliceosome, U1 regulates splicing in a similar fashion to that of auxiliary splicing factors, usually inhibiting splicing by binding to the 5 'ss like elements, which were identified as ESSs in an unbiased screen ${ }^{152}$. For example, a 5'ss-like sequence in an intron of the ATM gene inhibits pseudo-exon splicing by recruiting U1 snRNP, and a mutation of this sequence causes ataxia telangiectasia ${ }^{190-192}$.

In addition to regulating splicing, the U1 snRNP also controls other RNA-processing pathways such as polyadenylation ${ }^{193,194}$. Using genome-wide analysis methods, U1 snRNP was found to protect premature RNA cleavage and polyadenylation at alternative polyadenylation sites in primary transcripts ${ }^{195-197}$. In certain cases, recruitment of a single U1 snRNP component (U1A) affected selection of the alternative polyadenylation site ${ }^{198,199}$. The precise mechanism by which U1 snRNP affects polyadenylation is not clear. Current models suggest that U1 may inhibit the cleavage or polyadenylation site or affect recognition of the polyadenylation signal by the cleavage and polyadenylation specificity factor (CPSF), a protein complex that cleaves mRNA at the $3^{\prime}$ end to facilitate subsequent polyadenylation ${ }^{200}$.

Another twist in U1 snRNP function is found during trans-splicing in lower eukaryotes, where a spliced leader (SL) RNA forms a U1-snRNP like complex that interacts with other snRNPs to direct the splicing of SL-RNA onto pre-mRNAs. In such cases, the SL RNP complex has a dual function and acts similarly to complex $\mathrm{E}$ which contains both U1 snRNP and pre-mRNA. Similarly to other snRNPs, the maturation of SL RNP also requires the SMN complex, involves both nuclear and cytoplasmic events ${ }^{201}$, and will subsequently interact with $\mathrm{U} 2$, U4, U5 and U6 snRNP to form the trans-spliceosome. This form of splicing is found in almost all genes in Trypanosoma and Caenorhabditis, and can be found in very low frequency in mammalian cells ${ }^{202}$. Interestingly, an artificial 'half exon' can be forced to trans-splice onto a normal human pre-mRNA with 
reasonable efficiency ${ }^{203}$, suggesting that trans-splicing probably uses a similar spliceosomal assembly pathway to direct the splicing reaction.

\section{Other influences on splicing}

The accessibility of splice sites or $c i s$-acting SREs can be influenced by pre-mRNA structures and binding proteins. For example, a stem-loop sequence located at the 5'ss of exon 10 of the human tau gene directly affects the usage of the $5^{\prime}$ ss. Stabilization of this stem-loop decreases exon 10 inclusion and, reciprocally, its destabilization increases exon 10 inclusion $^{154}$. Another example is the Dscam gene in Drosophila melanogaster, in which the secondary structure of the intron ensures mutually exclusive splicing of alternative exons ${ }^{155-157}$. It is unclear whether examples like this represent unusual cases, or are a general rule. Spliceosomes contain multiple DExD/H RNA helicases that can unwind RNA structures and remodel RNA-protein complexes ${ }^{158}$. Although the primary function of these helicases seems to be rearrangement of snRNA-snRNA and snRNA-protein interactions in the spliceosome, at least one helicase (DDX17/p72) might be able to remodel pre-mRNA structures, thus modulating alternative splicing ${ }^{159,160}$. General roles for RNA structures in splicing regulation have yet to be clearly defined, and the identification of such elements by high throughput methods should prove very useful ${ }^{161}$.

Because splicing of most introns happens co-transcriptionally ${ }^{162}$, alternative splicing is also affected by factors that control transcription initiation and elongation. For example, the rate of transcription elongation can affect splicing events; slow elongation rate generally promotes the inclusion of weak exons ${ }^{163,164}$. In addition, alternative splicing may also be affected by chromatin structure and nucleosome positioning. A large number of recent reports have provided interesting insights into the connections between splicing and transcription (for further details, see references 165,166 ).

\section{An integrated code for splicing regulation}

Traditional models of splicing regulation typically consider the interaction between cisacting SREs and their cognate factors as a one-to-one relationship. However, most splicing factors can recognize two or more SRE motifs and each SRE motif is bound by multiple alternative factors, supporting the idea that a complex network of protein-RNA interactions is responsible for splicing regulation 150,167 . This pattern of overlapping binding specificities may enable a variety of regulatory relationships between splicing regulators. Multiple proteins with similar splicing regulatory activities might bind the same motif, resulting in functional redundancy; alternatively, one factor might displace another factor with opposite activity to confer functional antagonism. For example, in HeLa cells, neuronal PTB (nPTB) can compensate for depletion of PTB ${ }^{168}$, whereas during neural development replacement of PTB by nPTB is thought to initiate an alternative splicing programme ${ }^{169}$. RNA-binding factors with overlapping specificities may also provide subtle fine-tuning of splicing levels. Importantly, the densely connected network of SREs and their cognate splicing factors suggests that individual exons are often controlled by multiple factors to achieve regulatory plasticity. To assemble a set of splicing regulatory rules (known as the 'splicing code'), computational models have been applied to integrate the actions of multiple splicing factors 
and SREs, thereby allowing splicing outcomes to be predicted from sequence information in the pre-mRNA ${ }^{152,170}$.

\section{Conclusions and perspectives}

A major challenge in the post-genomic age of molecular biology is to understand how a limited number of human genes can generate a proteome that has five times the number of proteins ${ }^{171}$. The spliceosome, which reads the information for splicing of each pre-mRNA transcript, is probably the most complicated RNA-protein complex inside the eukaryotic cell $^{172}$. Although important insights have been obtained during the past decade, there are still many unanswered questions about the biogenesis of this macromolecular machine. For example, the signalling factors that regulate snRNP biogenesis are poorly understood, as are the functions of many post-translational modifications of snRNP proteins. Moreover, a key question is how conformational and compositional changes within the spliceosome dictate splicing outcomes. Detailed studies of spliceosome dynamics should provide much needed answers.

Another important research goal is to understand the 'splicing code' by which exon inclusion or exclusion by the spliceosome is controlled in different tissues and cell types ${ }^{170}$. Recent advances in functional genomics have fuelled identification of the myriad of regulatory elements and splicing factors involved, providing the research community with a near-complete parts list of the splicing regulatory machinery. Integration of this information should help determine the mechanism by which the splicing code is read by the spliceosome and ultimately provide a better understanding of complicated gene expression networks.

\section{Acknowledgments}

Research in our laboratories is supported by NIH grants R01-GM053034 and R01-NS041617 (to A.G.M.), as well as R01-CA158283 and R21-AR061640 (to Z.W.). We apologize to those whose work could not be discussed, owing to space limitations.

\section{Glossary terms}

Tudor domains

Cajal bodies

Nuclear Speckles

Splice site
A conserved protein structural motifs that are thought to bind to methylated arginine or lysine residues, promoting physical interactions with their target proteins

Nuclear substructures that are highly enriched in pre-mRNA splicing factors. Thought to function as sites of ribonucleoprotein RNP assembly and remodelling

Sub-nuclear structures highly enriched in pre-mRNA splicing factors. At the ultrastructural level, they correspond to domains known as interchromatin granule clusters

The short sequences at exon-intron junctions of pre-mRNA, including the $5^{\prime}$ splice (splice donor) site and the $3^{\prime}$ splice (splice acceptor) site located at the beginning and the end of an intron, respectively 
Branch point

Exon definition

SR proteins

Heterogeneous nuclear RNP (hnRNP)
A loosely conserved short sequence usually located at $\sim 15-50 \mathrm{nt}$ upstream of the $3^{\prime}$ splice site, before a region rich in pyrimidines (C and $\mathrm{U}$ ). Most branch points include an adenine nucleotide as the site of lariat formation

One of two different modes of initial splice site pairing at the early stage of splicing. During exon definition, the U1 and U2 snRNPs interact to pair the splice sites across an exon. For some small introns, the U1 and U2 snRNPs interact to pair the splice sites across introns

Proteins that contain a domain with repeats of serine and arginine residues and one or more RNA recognition motifs (RRMs). Best known for their ability to bind ESEs and activate splicing, although some SR proteins also regulate transcription

A diverse class of ribonucleoproteins (RNPs) located in the cell nucleus, and primarily involved in post-transcriptional regulation of mRNAs. The hnRNP proteins are a class of RNA-binding factors, many of which shuttle between the nucleus and cytoplasm, that are involved in regulating the processing, stability and subcellular transport of mRNPs

\section{References}

1. Berget SM, Moore C, Sharp PA. Spliced segments at the $5^{\prime}$ terminus of adenovirus 2 late mRNA. Proceedings of the National Academy of Sciences of the United States of America. 1977; 74:31715. [PubMed: 269380]

2. Chow LT, Gelinas RE, Broker TR, Roberts RJ. An amazing sequence arrangement at the $5^{\prime}$ ends of adenovirus 2 messenger RNA. Cell. 1977; 12:1-8. [PubMed: 902310]

3. Lerner MR, Boyle JA, Mount SM, Wolin SL, Steitz JA. Are snRNPs involved in splicing? Nature. 1980; 283:220-4. [PubMed: 7350545]

4. Will CL, Luhrmann R. Spliceosome structure and function. Cold Spring Harbor perspectives in biology. 2011; 3

5. Jurica MS, Moore MJ. Pre-mRNA splicing: awash in a sea of proteins. Molecular cell. 2003; 12:514. [PubMed: 12887888]

6. Matera AG, Terns RM, Terns MP. Non-coding RNAs: lessons from the small nuclear and small nucleolar RNAs. Nat Rev Mol Cell Biol. 2007; 8:209-20. [PubMed: 17318225]

7. Henry RW, Mittal V, Ma B, Kobayashi R, Hernandez N. SNAP19 mediates the assembly of a functional core promoter complex (SNAPc) shared by RNA polymerases II and III. Genes Dev. 1998; 12:2664-72. [PubMed: 9732265]

8. Hung KH, Stumph WE. Regulation of snRNA gene expression by the Drosophila melanogaster small nuclear RNA activating protein complex (DmSNAPc). Crit Rev Biochem Mol Biol. 2011; 46:11-26. [PubMed: 20925482]

9. Hernandez N, Weiner AM. Formation of the $3^{\prime}$ end of U1 snRNA requires compatible snRNA promoter elements. Cell. 1986; 47:249-58. [PubMed: 3768956]

10. Egloff $S$, et al. The integrator complex recognizes a new double mark on the RNA polymerase II carboxyl-terminal domain. J Biol Chem. 2010; 285:20564-9. [PubMed: 20457598]

11. Egloff $S$, et al. Serine-7 of the RNA polymerase II CTD is specifically required for snRNA gene expression. Science. 2007; 318:1777-9. [PubMed: 18079403] 
12. Baillat D, et al. Integrator, a multiprotein mediator of small nuclear RNA processing, associates with the C-terminal repeat of RNA polymerase II. Cell. 2005; 123:265-76. [PubMed: 16239144]

13. Chen J, et al. An RNAi screen identifies additional members of the Drosophila Integrator complex and a requirement for cyclin C/Cdk8 in snRNA $3^{\prime}$-end formation. RNA. 2012; 18:2148-56. [PubMed: 23097424]

14. Weiner AM. E Pluribus Unum: $3^{\prime}$ end formation of polyadenylated mRNAs, histone mRNAs, and U snRNAs. Mol Cell. 2005; 20:168-70. [PubMed: 16246719]

15. Mandel CR, et al. Polyadenylation factor CPSF-73 is the pre-mRNA $3^{\prime}$-end-processing endonuclease. Nature. 2006; 444:953-6. [PubMed: 17128255]

16. Ezzeddine N, et al. A subset of Drosophila integrator proteins is essential for efficient U7 snRNA and spliceosomal snRNA 3'-end formation. Mol Cell Biol. 2011; 31:328-41. [PubMed: 21078872]

17. Boon KL, et al. prp8 mutations that cause human retinitis pigmentosa lead to a U5 snRNP maturation defect in yeast. Nat Struct Mol Biol. 2007; 14:1077-83. [PubMed: 17934474]

18. Murphy MW, Olson BL, Siliciano PG. The yeast splicing factor Prp40p contains functional leucine-rich nuclear export signals that are essential for splicing. Genetics. 2004; 166:53-65. [PubMed: 15020406]

19. Tkacz ID, et al. Identification of novel snRNA-specific Sm proteins that bind selectively to U2 and U4 snRNAs in Trypanosoma brucei. RNA. 2007; 13:30-43. [PubMed: 17105994]

20. Palfi Z, et al. SMN-assisted assembly of snRNP-specific Sm cores in trypanosomes. Genes Dev. 2009; 23:1650-64. [PubMed: 19605687]

21. Jae N, et al. snRNA-specific role of SMN in trypanosome snRNP biogenesis in vivo. RNA Biol. 2011; 8:90-100. [PubMed: 21282982]

22. Hernandez-Verdun D, Roussel P, Thiry M, Sirri V, Lafontaine DL. The nucleolus: structure/ function relationship in RNA metabolism. Wiley interdisciplinary reviews. RNA. 2010; 1:415-31. [PubMed: 21956940]

23. Ohno M. Size matters in RNA export. RNA Biol. 2012; 9:1413-7. [PubMed: 23187719]

24. Cullen BR. Nuclear RNA export. J Cell Sci. 2003; 116:587-97. [PubMed: 12538759]

25. Ohno M, Segref A, Kuersten S, Mattaj IW. Identity elements used in export of mRNAs. Mol Cell. 2002; 9:659-71. [PubMed: 11931772]

26. Masuyama K, Taniguchi I, Kataoka N, Ohno M. RNA length defines RNA export pathway. Genes Dev. 2004; 18:2074-85. [PubMed: 15314030]

27. Fuke H, Ohno M. Role of poly (A) tail as an identity element for mRNA nuclear export. Nucleic Acids Res. 2008; 36:1037-49. [PubMed: 18096623]

28. McCloskey A, Taniguchi I, Shinmyozu K, Ohno M. hnRNP C tetramer measures RNA length to classify RNA polymerase II transcripts for export. Science. 2012; 335:1643-6. [PubMed: 22461616]

29. Izaurralde $\mathrm{E}$, et al. A nuclear cap binding protein complex involved in pre-mRNA splicing. Cell. 1994; 78:657-68. [PubMed: 8069914]

30. Ohno M, Segref A, Bachi A, Wilm M, Mattaj IW. PHAX, a mediator of U snRNA nuclear export whose activity is regulated by phosphorylation. Cell. 2000; 101:187-98. [PubMed: 10786834]

31. Hallais M, et al. CBC-ARS2 stimulates 3 '-end maturation of multiple RNA families and favors cap-proximal processing. Nat Struct Mol Biol. 2013

32. Fornerod M, Ohno M, Yoshida M, Mattaj IW. CRM1 is an export receptor for leucine-rich nuclear export signals. Cell. 1997; 90:1051-60. [PubMed: 9323133]

33. Smith KP, Lawrence JB. Interactions of U2 gene loci and their nuclear transcripts with Cajal (coiled) bodies: evidence for PreU2 within Cajal bodies. Mol Biol Cell. 2000; 11:2987-98. [PubMed: 10982395]

34. Suzuki T, Izumi H, Ohno M. Cajal body surveillance of U snRNA export complex assembly. J Cell Biol. 2010; 190:603-12. [PubMed: 20733056]

35. Boulon S, et al. PHAX and CRM1 are required sequentially to transport U3 snoRNA to nucleoli. Mol Cell. 2004; 16:777-87. [PubMed: 15574332]

36. Frey MR, Matera AG. RNA-mediated interaction of Cajal bodies and U2 snRNA genes. J Cell Biol. 2001; 154:499-509. [PubMed: 11489914] 
37. Matera AG, Izaguire-Sierra M, Praveen K, Rajendra TK. Nuclear bodies: random aggregates of sticky proteins or crucibles of macromolecular assembly? Dev Cell. 2009; 17:639-47. [PubMed: 19922869]

38. Kitao S, et al. A compartmentalized phosphorylation/dephosphorylation system that regulates U snRNA export from the nucleus. Mol Cell Biol. 2008; 28:487-97. [PubMed: 17967890]

39. Meister G, Buhler D, Pillai R, Lottspeich F, Fischer U. A multiprotein complex mediates the ATPdependent assembly of spliceosomal U snRNPs. Nat Cell Biol. 2001; 3:945-9. [PubMed: 11715014]

40. Pellizzoni L, Yong J, Dreyfuss G. Essential role for the SMN complex in the specificity of snRNP assembly. Science. 2002; 298:1775-9. [PubMed: 12459587]

41. Massenet S, Pellizzoni L, Paushkin S, Mattaj IW, Dreyfuss G. The SMN complex is associated with snRNPs throughout their cytoplasmic assembly pathway. Mol Cell Biol. 2002; 22:6533-41. [PubMed: 12192051]

42. Narayanan U, Ospina JK, Frey MR, Hebert MD, Matera AG. SMN, the spinal muscular atrophy protein, forms a pre-import snRNP complex with snurportin1 and importin beta. Hum Mol Genet. 2002; 11:1785-95. [PubMed: 12095920]

43. Mouaikel J, et al. Interaction between the small-nuclear-RNA cap hypermethylase and the spinal muscular atrophy protein, survival of motor neuron. EMBO Rep. 2003; 4:616-22. [PubMed: 12776181]

44. Meister G, et al. Methylation of Sm proteins by a complex containing PRMT5 and the putative U snRNP assembly factor pICln. Curr Biol. 2001; 11:1990-4. [PubMed: 11747828]

45. Friesen WJ, et al. The methylosome, a 20S complex containing JBP1 and pICln, produces dimethylarginine-modified Sm proteins. Mol Cell Biol. 2001; 21:8289-300. [PubMed: 11713266]

46. Grimm C, et al. Structural Basis of Assembly Chaperone- Mediated snRNP Formation. Mol Cell. 2013; 49:692-703. [PubMed: 23333303]

47. Chari A, et al. An assembly chaperone collaborates with the SMN complex to generate spliceosomal SnRNPs. Cell. 2008; 135:497-509. [PubMed: 18984161]

48. Yong J, Kasim M, Bachorik JL, Wan L, Dreyfuss G. Gemin5 delivers snRNA precursors to the SMN complex for snRNP biogenesis. Mol Cell. 2010; 38:551-62. [PubMed: 20513430]

49. Raker VA, Plessel G, Luhrmann R. The snRNP core assembly pathway: identification of stable core protein heteromeric complexes and an snRNP subcore particle in vitro. EMBO J. 1996; 15:2256-69. [PubMed: 8641291]

50. Kambach C, et al. Crystal structures of two Sm protein complexes and their implications for the assembly of the spliceosomal snRNPs. Cell. 1999; 96:375-87. [PubMed: 10025403]

51. Leung AK, Nagai K, Li J. Structure of the spliceosomal U4 snRNP core domain and its implication for snRNP biogenesis. Nature. 2011; 473:536-9. [PubMed: 21516107]

52. Kroiss M, et al. Evolution of an RNP assembly system: a minimal SMN complex facilitates formation of UsnRNPs in Drosophila melanogaster. Proc Natl Acad Sci U S A. 2008; 105:1004550. [PubMed: 18621711]

53. Zhang R, et al. Structure of a key intermediate of the SMN complex reveals Gemin2's crucial function in snRNP assembly. Cell. 2011; 146:384-95. [PubMed: 21816274]

54. Liu Q, Fischer U, Wang F, Dreyfuss G. The spinal muscular atrophy disease gene product, SMN, and its associated protein SIP1 are in a complex with spliceosomal snRNP proteins. Cell. 1997; 90:1013-21. [PubMed: 9323129]

55. Buhler D, Raker V, Luhrmann R, Fischer U. Essential role for the tudor domain of SMN in spliceosomal U snRNP assembly: implications for spinal muscular atrophy. Hum Mol Genet. 1999; 8:2351-7. [PubMed: 10556282]

56. Pellizzoni L, Charroux B, Dreyfuss G. SMN mutants of spinal muscular atrophy patients are defective in binding to snRNP proteins. Proc Natl Acad Sci U S A. 1999; 96:11167-72. [PubMed: 10500148]

57. Hannus S, Buhler D, Romano M, Seraphin B, Fischer U. The Schizosaccharomyces pombe protein Yab8p and a novel factor, Yip1p, share structural and functional similarity with the spinal muscular atrophy-associated proteins SMN and SIP1. Hum Mol Genet. 2000; 9:663-74. [PubMed: 10749973] 
58. Rajendra TK, et al. A Drosophila melanogaster model of spinal muscular atrophy reveals a function for SMN in striated muscle. J Cell Biol. 2007; 176:831-41. [PubMed: 17353360]

59. Shpargel KB, Matera AG. Gemin proteins are required for efficient assembly of Sm-class ribonucleoproteins. Proceedings of the National Academy of Sciences of the United States of America. 2005; 102:17372-7. [PubMed: 16301532]

60. Selenko P, et al. SMN tudor domain structure and its interaction with the Sm proteins. Nat Struct Biol. 2001; 8:27-31. [PubMed: 11135666]

61. Lorson CL, et al. SMN oligomerization defect correlates with spinal muscular atrophy severity. Nat Genet. 1998; 19:63-6. [PubMed: 9590291]

62. Martin R, Gupta K, Ninan NS, Perry K, Van Duyne GD. The survival motor neuron protein forms soluble glycine zipper oligomers. Structure. 2012; 20:1929-39. [PubMed: 23022347]

63. Fischer U, Luhrmann R. An essential signaling role for the $\mathrm{m} 3 \mathrm{G}$ cap in the transport of U1 snRNP to the nucleus. Science. 1990; 249:786-90. [PubMed: 2143847]

64. Narayanan U, Achsel T, Luhrmann R, Matera AG. Coupled in vitro import of U snRNPs and SMN, the Spinal Muscular Atrophy protein. Mol Cell. 2004; 16:223-34. [PubMed: 15494309]

65. Fischer U, Sumpter V, Sekine M, Satoh T, Luhrmann R. Nucleo-cytoplasmic transport of U snRNPs: definition of a nuclear location signal in the Sm core domain that binds a transport receptor independently of the m3G cap. EMBO J. 1993; 12:573-83. [PubMed: 7679989]

66. Huber J, et al. Snurportin1, an m3G-cap-specific nuclear import receptor with a novel domain structure. EMBO J. 1998; 17:4114-26. [PubMed: 9670026]

67. Palacios I, Hetzer M, Adam SA, Mattaj IW. Nuclear import of U snRNPs requires importin beta. EMBO J. 1997; 16:6783-92. [PubMed: 9362492]

68. Fischer U, Liu Q, Dreyfuss G. The SMN-SIP1 complex has an essential role in spliceosomal snRNP biogenesis. Cell. 1997; 90:1023-9. [PubMed: 9323130]

69. Neubauer G, et al. Mass spectrometry and EST-database searching allows characterization of the multi-protein spliceosome complex. Nat Genet. 1998; 20:46-50. [PubMed: 9731529]

70. Trinkle-Mulcahy L, et al. Identifying specific protein interaction partners using quantitative mass spectrometry and bead proteomes. J Cell Biol. 2008; 183:223-39. [PubMed: 18936248]

71. Herold N, et al. Conservation of the protein composition and electron microscopy structure of Drosophila melanogaster and human spliceosomal complexes. Mol Cell Biol. 2009; 29:281-301. [PubMed: 18981222]

72. Matera AG, Shpargel KB. Pumping RNA: nuclear bodybuilding along the RNP pipeline. Curr Opin Cell Biol. 2006; 18:317-24. [PubMed: 16632338]

73. Stanek D, Neugebauer KM. The Cajal body: a meeting place for spliceosomal snRNPs in the nuclear maze. Chromosoma. 2006; 115:343-54. [PubMed: 16575476]

74. Sleeman JE, Lamond AI. Newly assembled snRNPs associate with coiled bodies before speckles, suggesting a nuclear snRNP maturation pathway. Curr Biol. 1999; 9:1065-74. [PubMed: 10531003]

75. Lamond AI, Spector DL. Nuclear speckles: a model for nuclear organelles. Nat Rev Mol Cell Biol. 2003; 4:605-12. [PubMed: 12923522]

76. Ospina JK, et al. Cross-talk between snurportin1 subdomains. Mol Biol Cell. 2005; 16:4660-71. [PubMed: 16030253]

77. Jady BE, et al. Modification of Sm small nuclear RNAs occurs in the nucleoplasmic Cajal body following import from the cytoplasm. EMBO J. 2003; 22:1878-88. [PubMed: 12682020]

78. Nesic D, Tanackovic G, Kramer A. A role for Cajal bodies in the final steps of U2 snRNP biogenesis. J Cell Sci. 2004; 117:4423-33. [PubMed: 15316075]

79. Schaffert N, Hossbach M, Heintzmann R, Achsel T, Luhrmann R. RNAi knockdown of hPrp31 leads to an accumulation of U4/U6 di-snRNPs in Cajal bodies. Embo J. 2004; 23:3000-9. [PubMed: 15257298]

80. Novotny I, Blazikova M, Stanek D, Herman P, Malinsky J. In vivo kinetics of U4/U6.U5 trisnRNP formation in Cajal bodies. Mol Biol Cell. 2011; 22:513-23. [PubMed: 21177826]

81. Stanek D, Neugebauer KM. Detection of snRNP assembly intermediates in Cajal bodies by fluorescence resonance energy transfer. J Cell Biol. 2004; 166:1015-25. [PubMed: 15452143] 
82. Stanek D, Rader SD, Klingauf M, Neugebauer KM. Targeting of U4/U6 small nuclear RNP assembly factor SART3/p110 to Cajal bodies. J Cell Biol. 2003; 160:505-16. [PubMed: 12578909]

83. Lemm I, et al. Ongoing U snRNP biogenesis is required for the integrity of Cajal bodies. Mol Biol Cell. 2006; 17:3221-31. [PubMed: 16687569]

84. Strzelecka M, Oates AC, Neugebauer KM. Dynamic control of Cajal body number during zebrafish embryogenesis. Nucleus. 2010; 1:96-108. [PubMed: 21327108]

85. Takata H, Nishijima H, Maeshima K, Shibahara K. The integrator complex is required for integrity of Cajal bodies. J Cell Sci. 2012; 125:166-75. [PubMed: 22250197]

86. Tucker KE, et al. Residual Cajal bodies in coilin knockout mice fail to recruit Sm snRNPs and SMN, the spinal muscular atrophy gene product. J Cell Biol. 2001; 154:293-307. [PubMed: 11470819]

87. Liu JL, et al. Coilin is essential for Cajal body organization in Drosophila melanogaster. Mol Biol Cell. 2009; 20:1661-70. [PubMed: 19158395]

88. Walker MP, Tian L, Matera AG. Reduced viability, fertility and fecundity in mice lacking the cajal body marker protein, coilin. PLoS One. 2009; 4:e6171. [PubMed: 19587784]

89. Strzelecka M, et al. Coilin-dependent snRNP assembly is essential for zebrafish embryogenesis. Nat Struct Mol Biol. 2010; 17:403-9. [PubMed: 20357773]

90. Spector DL, Lamond AI. Nuclear Speckles. Cold Spring Harb Perspect Biol. 2011

91. Hall LL, Smith KP, Byron M, Lawrence JB. Molecular anatomy of a speckle. Anat Rec A Discov Mol Cell Evol Biol. 2006; 288:664-75. [PubMed: 16761280]

92. Girard C, et al. Post-transcriptional spliceosomes are retained in nuclear speckles until splicing completion. Nature communications. 2012; 3:994.

93. Valadkhan S. Role of the snRNAs in spliceosomal active site. RNA biology. 2010; 7:345-53. [PubMed: 20458185]

94. Du H, Rosbash M. The U1 snRNP protein U1C recognizes the $5^{\prime}$ splice site in the absence of base pairing. Nature. 2002; 419:86-90. [PubMed: 12214237]

95. Wiesner S, Stier G, Sattler M, Macias MJ. Solution structure and ligand recognition of the WW domain pair of the yeast splicing factor Prp40. Journal of molecular biology. 2002; 324:807-22. [PubMed: 12460579]

96. Morris DP, Greenleaf AL. The splicing factor, Prp40, binds the phosphorylated carboxyl-terminal domain of RNA polymerase II. The Journal of biological chemistry. 2000; 275:39935-43. [PubMed: 10978320]

97. Gornemann J, et al. Cotranscriptional spliceosome assembly and splicing are independent of the Prp40p WW domain. RNA. 2011; 17:2119-29. [PubMed: 22020974]

98. Staknis D, Reed R. SR proteins promote the first specific recognition of Pre-mRNA and are present together with the U1 small nuclear ribonucleoprotein particle in a general splicing enhancer complex. Molecular and cellular biology. 1994; 14:7670-82. [PubMed: 7935481]

99. Cho S, et al. Interaction between the RNA binding domains of Ser-Arg splicing factor 1 and U1-70K snRNP protein determines early spliceosome assembly. Proceedings of the National Academy of Sciences of the United States of America. 2011; 108:8233-8. [PubMed: 21536904]

100. Pabis M, et al. The nuclear cap-binding complex interacts with the U4/U6.U5 tri-snRNP and promotes spliceosome assembly in mammalian cells. RNA. 2013; 19:1054-63. [PubMed: 23793891]

101. Fox-Walsh KL, et al. The architecture of pre-mRNAs affects mechanisms of splice-site pairing. Proceedings of the National Academy of Sciences of the United States of America. 2005; 102:16176-81. [PubMed: 16260721]

102. Xiao X, Wang Z, Jang M, Burge CB. Coevolutionary networks of splicing cis-regulatory elements. Proceedings of the National Academy of Sciences of the United States of America. 2007; 104:18583-8. [PubMed: 17998536]

103. Sterner DA, Carlo T, Berget SM. Architectural limits on split genes. Proc Natl Acad Sci U S A. 1996; 93:15081-5. [PubMed: 8986767] 
104. De Conti L, Baralle M, Buratti E. Exon and intron definition in pre-mRNA splicing. Wiley interdisciplinary reviews. RNA. 2013; 4:49-60. [PubMed: 23044818]

105. Bonnal S, et al. RBM5/Luca-15/H37 regulates Fas alternative splice site pairing after exon definition. Molecular cell. 2008; 32:81-95. [PubMed: 18851835]

106. Sharma S, Kohlstaedt LA, Damianov A, Rio DC, Black DL. Polypyrimidine tract binding protein controls the transition from exon definition to an intron defined spliceosome. Nature structural \& molecular biology. 2008; 15:183-91.

107. Sun JS, Manley JL. A novel U2-U6 snRNA structure is necessary for mammalian mRNA splicing. Genes Dev. 1995; 9:843-54. [PubMed: 7705661]

108. Raghunathan PL, Guthrie C. RNA unwinding in U4/U6 snRNPs requires ATP hydrolysis and the DEIH-box splicing factor Brr2. Current biology: CB. 1998; 8:847-55. [PubMed: 9705931]

109. Ilagan JO, Chalkley RJ, Burlingame AL, Jurica MS. Rearrangements within human spliceosomes captured after exon ligation. RNA. 2013

110. Schwer B, Gross CH. Prp22, a DExH-box RNA helicase, plays two distinct roles in yeast premRNA splicing. EMBO J. 1998; 17:2086-94. [PubMed: 9524130]

111. Fourmann JB, et al. Dissection of the factor requirements for spliceosome disassembly and the elucidation of its dissociation products using a purified splicing system. Genes Dev. 2013; 27:413-28. [PubMed: 23431055]

112. Abelson J, et al. Conformational dynamics of single pre-mRNA molecules during in vitro splicing. Nature structural \& molecular biology. 2010; 17:504-12.

113. Hoskins AA, et al. Ordered and dynamic assembly of single spliceosomes. Science. 2011; 331:1289-95. [PubMed: 21393538]

114. Tseng CK, Cheng SC. Both catalytic steps of nuclear pre-mRNA splicing are reversible. Science. 2008; 320:1782-4. [PubMed: 18583613]

115. Yang F, et al. Splicing proofreading at $5^{\prime}$ splice sites by ATPase Prp28p. Nucleic acids research. 2013; 41:4660-70. [PubMed: 23462954]

116. Malca H, Shomron N, Ast G. The U1 snRNP base pairs with the $5^{\prime}$ splice site within a pentasnRNP complex. Molecular and cellular biology. 2003; 23:3442-55. [PubMed: 12724403]

117. Stevens SW, et al. Composition and functional characterization of the yeast spliceosomal pentasnRNP. Mol Cell. 2002; 9:31-44. [PubMed: 11804584]

118. Gornemann J, Kotovic KM, Hujer K, Neugebauer KM. Cotranscriptional spliceosome assembly occurs in a stepwise fashion and requires the cap binding complex. Molecular cell. 2005; 19:5363. [PubMed: 15989964]

119. Behzadnia N, Hartmuth K, Will CL, Luhrmann R. Functional spliceosomal A complexes can be assembled in vitro in the absence of a penta-snRNP. RNA. 2006; 12:1738-46. [PubMed: 16880538]

120. Schneider M, et al. Exon definition complexes contain the tri-snRNP and can be directly converted into B-like precatalytic splicing complexes. Molecular cell. 2010; 38:223-35. [PubMed: 20417601]

121. Madhani HD, Guthrie C. Dynamic RNA-RNA interactions in the spliceosome. Annual review of genetics. 1994; 28:1-26.

122. Valadkhan S, Mohammadi A, Wachtel C, Manley JL. Protein-free spliceosomal snRNAs catalyze a reaction that resembles the first step of splicing. RNA. 2007; 13:2300-11. [PubMed: 17940139]

123. Valadkhan S, Mohammadi A, Jaladat Y, Geisler S. Protein-free small nuclear RNAs catalyze a two-step splicing reaction. Proceedings of the National Academy of Sciences of the United States of America. 2009; 106:11901-6. [PubMed: 19549866]

124. Marcia M, Pyle AM. Visualizing group II intron catalysis through the stages of splicing. Cell. 2012; 151:497-507. [PubMed: 23101623]

125. Toor N, Keating KS, Pyle AM. Structural insights into RNA splicing. Current opinion in structural biology. 2009; 19:260-6. [PubMed: 19443210]

126. Toor N, Keating KS, Taylor SD, Pyle AM. Crystal structure of a self-spliced group II intron. Science. 2008; 320:77-82. [PubMed: 18388288] 
127. Fica SM, et al. RNA catalyses nuclear pre-mRNA splicing. Nature. 2013; 503:229-34. [PubMed: 24196718]

128. Butcher SE. The spliceosome and its metal ions. Metal ions in life sciences. 2011; 9:235-51. [PubMed: 22010274]

129. Cordin O, Hahn D, Beggs JD. Structure, function and regulation of spliceosomal RNA helicases. Current opinion in cell biology. 2012; 24:431-8. [PubMed: 22464735]

130. Small EC, Leggett SR, Winans AA, Staley JP. The EF-G-like GTPase Snu114p regulates spliceosome dynamics mediated by Brr2p, a DExD/H box ATPase. Molecular cell. 2006; 23:389-99. [PubMed: 16885028]

131. Galej WP, Oubridge C, Newman AJ, Nagai K. Crystal structure of Prp8 reveals active site cavity of the spliceosome. Nature. 2013; 493:638-43. [PubMed: 23354046]

132. Schellenberg MJ, et al. A conformational switch in PRP8 mediates metal ion coordination that promotes pre-mRNA exon ligation. Nature structural \& molecular biology. 2013; 20:728-34.

133. Mozaffari-Jovin S, et al. Inhibition of RNA helicase Brr2 by the C-terminal tail of the spliceosomal protein Prp8. Science. 2013; 341:80-4. [PubMed: 23704370]

134. Ohrt T, et al. Molecular dissection of step 2 catalysis of yeast pre-mRNA splicing investigated in a purified system. RNA. 2013; 19:902-15. [PubMed: 23685439]

135. Sun H, Chasin LA. Multiple splicing defects in an intronic false exon. Mol Cell Biol. 2000; 20:6414-25. [PubMed: 10938119]

136. Matlin AJ, Clark F, Smith CW. Understanding alternative splicing: towards a cellular code. Nature reviews Molecular cell biology. 2005; 6:386-98.

137. Wang Z, Burge CB. Splicing regulation: from a parts list of regulatory elements to an integrated splicing code. RNA. 2008; 14:802-13. [PubMed: 18369186]

138. Bessonov S, Anokhina M, Will CL, Urlaub H, Luhrmann R. Isolation of an active step I spliceosome and composition of its RNP core. Nature. 2008; 452:846-50. [PubMed: 18322460]

139. Zhou Z, Licklider LJ, Gygi SP, Reed R. Comprehensive proteomic analysis of the human spliceosome. Nature. 2002; 419:182-5. [PubMed: 12226669]

140. Hegele A, et al. Dynamic protein-protein interaction wiring of the human spliceosome. Molecular cell. 2012; 45:567-80. [PubMed: 22365833]

141. Izquierdo JM, et al. Regulation of Fas alternative splicing by antagonistic effects of TIA-1 and PTB on exon definition. Molecular cell. 2005; 19:475-84. [PubMed: 16109372]

142. Sharma S, Maris C, Allain FH, Black DL. U1 snRNA directly interacts with polypyrimidine tractbinding protein during splicing repression. Molecular cell. 2011; 41:579-88. [PubMed: 21362553]

143. Chiou NT, Shankarling G, Lynch KW. HnRNP L and HnRNP A1 Induce Extended U1 snRNA Interactions with an Exon to Repress Spliceosome Assembly. Molecular cell. 2013

144. House AE, Lynch KW. An exonic splicing silencer represses spliceosome assembly after ATPdependent exon recognition. Nature structural \& molecular biology. 2006; 13:937-44.

145. McCullough AJ, Berget SM. G triplets located throughout a class of small vertebrate introns enforce intron borders and regulate splice site selection. Mol Cell Biol. 1997; 17:4562-71. [PubMed: 9234714]

146. Chou MY, Rooke N, Turck CW, Black DL. hnRNP H is a component of a splicing enhancer complex that activates a c-src alternative exon in neuronal cells. Mol Cell Biol. 1999; 19:69-77. [PubMed: 9858532]

147. Chen CD, Kobayashi R, Helfman DM. Binding of hnRNP H to an exonic splicing silencer is involved in the regulation of alternative splicing of the rat beta-tropomyosin gene. Genes Dev. 1999; 13:593-606. [PubMed: 10072387]

148. Caputi M, Zahler AM. Determination of the RNA binding specificity of the heterogeneous nuclear ribonucleoprotein (hnRNP) H/H'/F/2H9 family. J Biol Chem. 2001; 276:43850-9. [PubMed: 11571276]

149. Ule J, et al. An RNA map predicting Nova-dependent splicing regulation. Nature. 2006; 444:5806. [PubMed: 17065982] 
150. Wang Y, et al. A complex network of factors with overlapping affinities represses splicing through intronic elements. Nat Struct Mol Biol. 2013; 20:36-45. [PubMed: 23241926]

151. Borah S, Wong AC, Steitz JA. Drosophila hnRNP A1 homologs Hrp36/Hrp38 enhance U2-type versus U12-type splicing to regulate alternative splicing of the prospero twintron. Proceedings of the National Academy of Sciences of the United States of America. 2009; 106:2577-82. [PubMed: 19196985]

152. Wang Z, et al. Systematic identification and analysis of exonic splicing silencers. Cell. 2004; 119:831-45. [PubMed: 15607979]

153. Yu Y, et al. Dynamic regulation of alternative splicing by silencers that modulate $5^{\prime}$ splice site competition. Cell. 2008; 135:1224-36. [PubMed: 19109894]

154. Donahue CP, Muratore C, Wu JY, Kosik KS, Wolfe MS. Stabilization of the tau exon 10 stem loop alters pre-mRNA splicing. J Biol Chem. 2006; 281:23302-6. [PubMed: 16782711]

155. Graveley BR. Mutually exclusive splicing of the insect Dscam pre-mRNA directed by competing intronic RNA secondary structures. Cell. 2005; 123:65-73. [PubMed: 16213213]

156. Yang Y, et al. RNA secondary structure in mutually exclusive splicing. Nat Struct Mol Biol. 2011; 18:159-68. [PubMed: 21217700]

157. Wang X, et al. An RNA architectural locus control region involved in Dscam mutually exclusive splicing. Nature communications. 2012; 3:1255.

158. Bleichert F, Baserga SJ. The long unwinding road of RNA helicases. Mol Cell. 2007; 27:339-52. [PubMed: 17679086]

159. Honig A, Auboeuf D, Parker MM, O'Malley BW, Berget SM. Regulation of alternative splicing by the ATP-dependent DEAD-box RNA helicase p72. Mol Cell Biol. 2002; 22:5698-707. [PubMed: 12138182]

160. Lee CG. RH70, a bidirectional RNA helicase, co-purifies with U1snRNP. J Biol Chem. 2002; 277:39679-83. [PubMed: 12193588]

161. Weeks KM. Advances in RNA structure analysis by chemical probing. Current opinion in structural biology. 2010; 20:295-304. [PubMed: 20447823]

162. Khodor YL, et al. Nascent-seq indicates widespread cotranscriptional pre-mRNA splicing in Drosophila. Genes \& development. 2011; 25:2502-12. [PubMed: 22156210]

163. Ip JY, et al. Global impact of RNA polymerase II elongation inhibition on alternative splicing regulation. Genome research. 2011; 21:390-401. [PubMed: 21163941]

164. Roberts GC, Gooding C, Mak HY, Proudfoot NJ, Smith CW. Co-transcriptional commitment to alternative splice site selection. Nucleic acids research. 1998; 26:5568-72. [PubMed: 9837984]

165. Kornblihtt AR, et al. Alternative splicing: a pivotal step between eukaryotic transcription and translation. Nature reviews. Molecular cell biology. 2013; 14:153-65.

166. Brugiolo M, Herzel L, Neugebauer KM. Counting on co-transcriptional splicing. F1000prime reports. 2013; 5:9. [PubMed: 23638305]

167. Wang Y, Ma M, Xiao X, Wang Z. Intronic splicing enhancers, cognate splicing factors and context-dependent regulation rules. Nat Struct Mol Biol. 2012

168. Spellman R, Llorian M, Smith CW. Crossregulation and functional redundancy between the splicing regulator PTB and its paralogs $\mathrm{nPTB}$ and ROD1. Mol Cell. 2007; 27:420-34. [PubMed: 17679092]

169. Boutz PL, et al. A post-transcriptional regulatory switch in polypyrimidine tract-binding proteins reprograms alternative splicing in developing neurons. Genes Dev. 2007; 21:1636-52. [PubMed: 17606642]

170. Barash Y, et al. Deciphering the splicing code. Nature. 2010; 465:53-9. [PubMed: 20445623]

171. Nilsen TW, Graveley BR. Expansion of the eukaryotic proteome by alternative splicing. Nature. 2010; 463:457-63. [PubMed: 20110989]

172. Nilsen TW. The spliceosome: the most complex macromolecular machine in the cell? BioEssays: news and reviews in molecular, cellular and developmental biology. 2003; 25:1147-9.

173. Smith ER, et al. The little elongation complex regulates small nuclear RNA transcription. Mol Cell. 2011; 44:954-65. [PubMed: 22195968] 
174. Fabrizio $P$, et al. The evolutionarily conserved core design of the catalytic activation step of the yeast spliceosome. Mol Cell. 2009; 36:593-608. [PubMed: 19941820]

175. Singh RK, Cooper TA. Pre-mRNA splicing in disease and therapeutics. Trends Mol Med. 2012; 18:472-82. [PubMed: 22819011]

176. Padgett RA. New connections between splicing and human disease. Trends Genet. 2012; 28:14754. [PubMed: 22397991]

177. Tanackovic G, et al. PRPF mutations are associated with generalized defects in spliceosome formation and pre-mRNA splicing in patients with retinitis pigmentosa. Human molecular genetics. 2011; 20:2116-30. [PubMed: 21378395]

178. Utz VM, Beight CD, Marino MJ, Hagstrom SA, Traboulsi EI. Autosomal Dominant Retinitis Pigmentosa Secondary to Pre-mRNA Splicing-Factor Gene PRPF31 (RP11): Review of Disease Mechanism and Report of a Family with a Novel 3-Base Pair Insertion. Ophthalmic genetics. 2013

179. Pena V, Liu S, Bujnicki JM, Luhrmann R, Wahl MC. Structure of a multipartite protein-protein interaction domain in splicing factor prp8 and its link to retinitis pigmentosa. Molecular cell. 2007; 25:615-24. [PubMed: 17317632]

180. He H, et al. Mutations in U4atac snRNA, a component of the minor spliceosome, in the developmental disorder MOPD I. Science. 2011; 332:238-40. [PubMed: 21474760]

181. Lorson CL, Hahnen E, Androphy EJ, Wirth B. A single nucleotide in the SMN gene regulates splicing and is responsible for spinal muscular atrophy. Proceedings of the National Academy of Sciences of the United States of America. 1999; 96:6307-11. [PubMed: 10339583]

182. Schrank B, et al. Inactivation of the survival motor neuron gene, a candidate gene for human spinal muscular atrophy, leads to massive cell death in early mouse embryos. Proc Natl Acad Sci U S A. 1997; 94:9920-5. [PubMed: 9275227]

183. Gabanella F, et al. Ribonucleoprotein assembly defects correlate with spinal muscular atrophy severity and preferentially affect a subset of spliceosomal snRNPs. PLoS One. 2007; 2:e921. [PubMed: 17895963]

184. Praveen K, Wen Y, Matera AG. A Drosophila model of spinal muscular atrophy uncouples snRNP biogenesis functions of survival motor neuron from locomotion and viability defects. Cell Rep. 2012; 1:624-31. [PubMed: 22813737]

185. Garcia EL, Lu Z, Meers MP, Praveen K, Matera AG. Developmental arrest of Drosophila survival motor neuron (Smn) mutants accounts for differences in expression of minor introncontaining genes. RNA. 2013; 19 in press.

186. Baumer D, et al. Alternative splicing events are a late feature of pathology in a mouse model of spinal muscular atrophy. PLoS Genet. 2009; 5:e1000773. [PubMed: 20019802]

187. Cazzola M, Rossi M, Malcovati L. Biologic and clinical significance of somatic mutations of SF3B1 in myeloid and lymphoid neoplasms. Blood. 2013; 121:260-9. [PubMed: 23160465]

188. Yoshida K, et al. Frequent pathway mutations of splicing machinery in myelodysplasia. Nature. 2011; 478:64-9. [PubMed: 21909114]

189. Chesnais V, et al. Spliceosome mutations in myelodysplastic syndromes and chronic myelomonocytic leukemia. Oncotarget. 2012; 3:1284-93. [PubMed: 23327988]

190. Dhir A, Buratti E, van Santen MA, Luhrmann R, Baralle FE. The intronic splicing code: multiple factors involved in ATM pseudoexon definition. EMBO J. 2010; 29:749-60. [PubMed: 20094034]

191. Lewandowska MA, Stuani C, Parvizpur A, Baralle FE, Pagani F. Functional studies on the ATM intronic splicing processing element. Nucleic Acids Res. 2005; 33:4007-15. [PubMed: 16030351]

192. Pagani F, et al. A new type of mutation causes a splicing defect in ATM. Nat Genet. 2002; 30:426-9. [PubMed: 11889466]

193. Gunderson SI, Polycarpou-Schwarz M, Mattaj IW. U1 snRNP inhibits pre-mRNA polyadenylation through a direct interaction between $\mathrm{U} 170 \mathrm{~K}$ and poly(A) polymerase. Mol Cell. 1998; 1:255-64. [PubMed: 9659922]

194. Langemeier J, Radtke M, Bohne J. U1 snRNP-mediated poly(A) site suppression: Beneficial and deleterious for mRNA fate. RNA Biol. 2013; 10 
195. Kaida D, et al. U1 snRNP protects pre-mRNAs from premature cleavage and polyadenylation. Nature. 2010; 468:664-8. [PubMed: 20881964]

196. Almada AE, Wu X, Kriz AJ, Burge CB, Sharp PA. Promoter directionality is controlled by U1 snRNP and polyadenylation signals. Nature. 2013; 499:360-3. [PubMed: 23792564]

197. Berg MG, et al. U1 snRNP determines mRNA length and regulates isoform expression. Cell. 2012; 150:53-64. [PubMed: 22770214]

198. Peterson ML, Bingham GL, Cowan C. Multiple features contribute to the use of the immunoglobulin $\mathrm{M}$ secretion-specific poly(A) signal but are not required for developmental regulation. Mol Cell Biol. 2006; 26:6762-71. [PubMed: 16943419]

199. Hall-Pogar T, Liang S, Hague LK, Lutz CS. Specific trans-acting proteins interact with auxiliary RNA polyadenylation elements in the COX-2 3'-UTR. RNA. 2007; 13:1103-15. [PubMed: 17507659]

200. Luo W, et al. The Conserved Intronic Cleavage and Polyadenylation Site of CstF-77 Gene Imparts Control of $3^{\prime}$ End Processing Activity through Feedback Autoregulation and by U1 snRNP. PLoS genetics. 2013; 9:e1003613. [PubMed: 23874216]

201. Michaeli S. Trans-splicing in trypanosomes: machinery and its impact on the parasite transcriptome. Future microbiology. 2011; 6:459-74. [PubMed: 21526946]

202. Lasda EL, Blumenthal T. Trans-splicing. Wiley interdisciplinary reviews. RNA. 2011; 2:417-34. [PubMed: 21957027]

203. Bruzik JP, Maniatis T. Spliced leader RNAs from lower eukaryotes are trans-spliced in mammalian cells. Nature. 1992; 360:692-5. [PubMed: 1465136] 


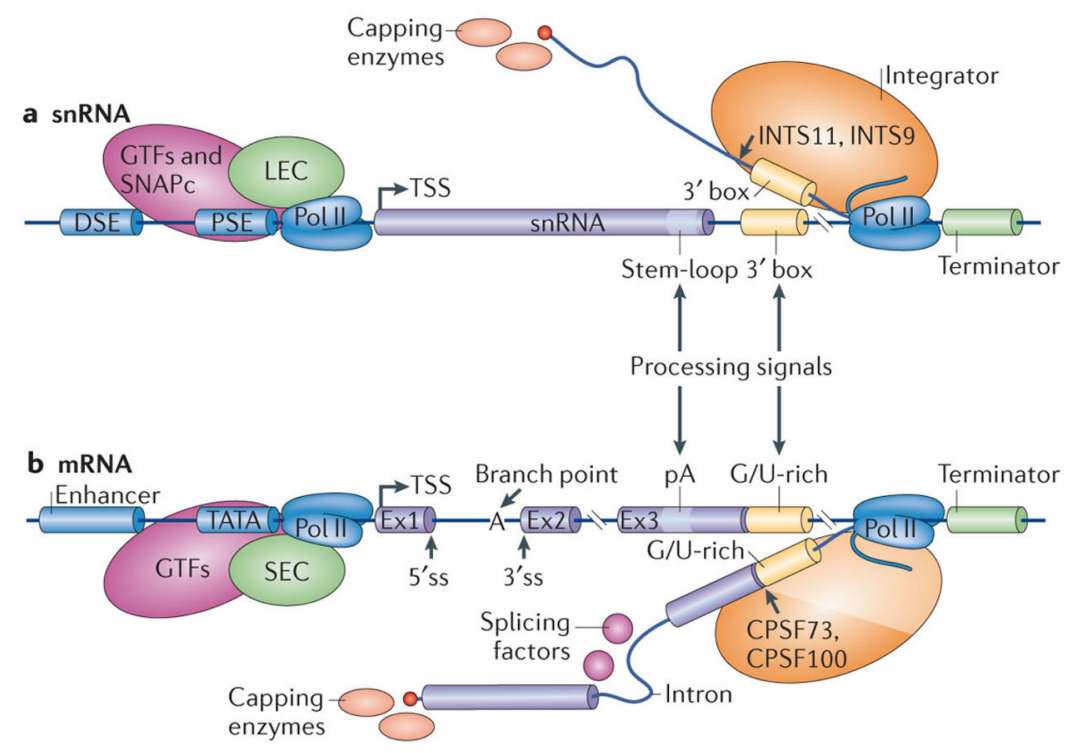

Figure 1. Comparison of transcription and processing of snRNAs and mRNAs

Sm-class snRNA genes (a) share a number of common features with protein-coding mRNA genes (b), including the arrangement of upstream and downstream control elements. The cis-acting elements and trans-acting factors involved in expression of these two types of transcripts are depicted. The DSE (distal sequence element) and PSE (proximal sequence element) are roughly equivalent to the enhancer and TATA box elements, respectively, of mRNA genes. Positive transcription elongation factor $\mathrm{b}$ ( $\mathrm{P}-\mathrm{TEFb}$; not shown) is recruited to both promoters by RNA pol II. In addition, snRNA promoters recruit the LEC (little elongation complex), whereas mRNA promoters recruit the SEC (super elongation complex $)^{173}$. Initiation of snRNA transcription requires general transcription factors (GTFs) as well as the snRNA-activating protein complex (SNAPc). The Integrator complex is required for recognition of snRNA downstream processing signals, including the $3^{\prime}$ box. Two of its subunits, IntS11 and IntS9, share sequence similarity to the mRNA $3^{\prime}$ processing factors CPSF73 and CPSF100. For both snRNAs and mRNAs, $5^{\prime}$ end capping and $3^{\prime}$ end cleavage are thought to occur co-transcriptionally. Additional processing factors (not shown) are recruited to the nascent transcripts via interactions with the pol II C-terminal domain. 


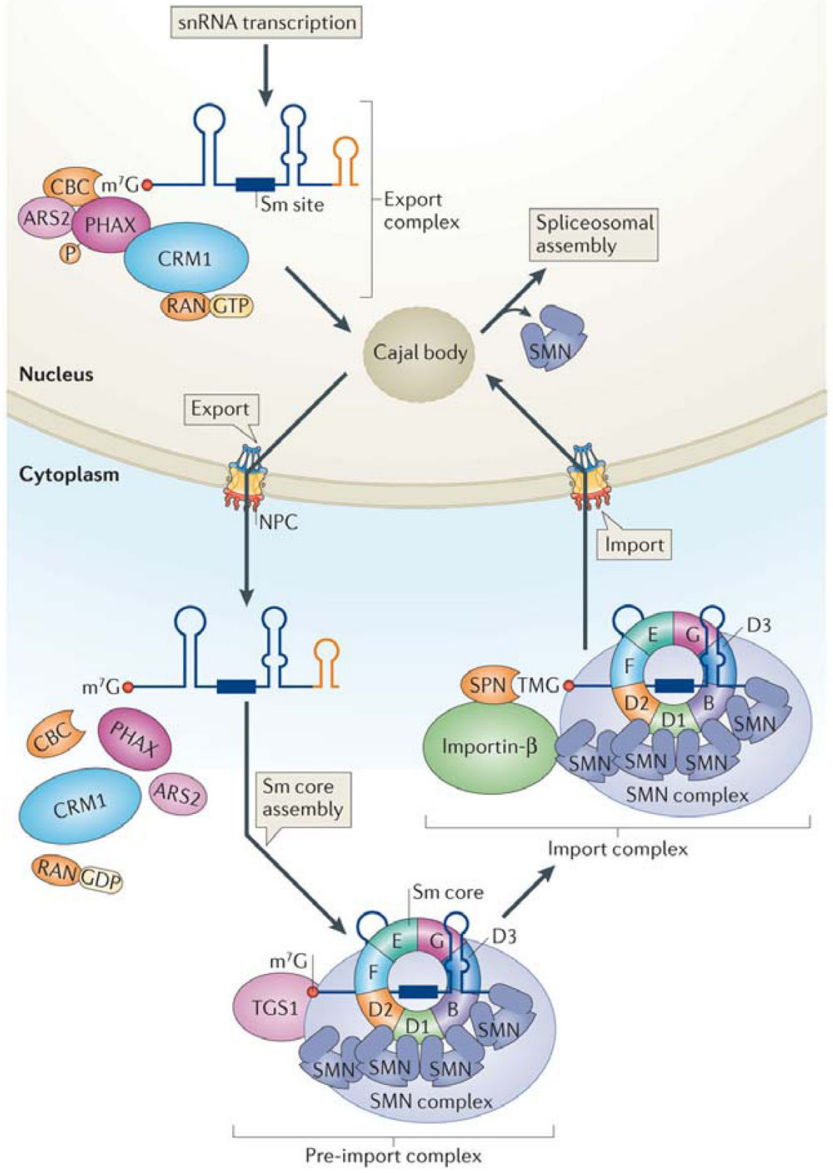

Figure 2. Maturation of snRNAs requires nuclear and cytoplasmic regulatory steps The snRNA pre-export complex consists of the heterodimeric cap-binding complex (CBC), arsenite resistance protein 2 (ARS2), the hyperphosphorylated form of the export adaptor PHAX and the large multi-subunit Integrator complex (not shown). Upon release from the site of snRNA transcription, the pre-export complex is remodelled within the nucleoplasm to form the export complex. This step involves removal of Integrator proteins and binding of the export receptor CRM1 (chromosome region maintenance 1) and the GTP-bound form of the RAN GTPase. Nucleoplasmic remodelling probably includes a Cajal body-mediated surveillance step to ensure RNP quality. Once transported to the cytoplasm, these export factors dissociate from the pre-snRNA prior to Sm core assembly and exonucleolytic trimming of the snRNA $3^{\prime}$ end (orange stem sloop). Following assembly of the Sm core snRNP (detailed in Fig. 3), the 7-methylguanosine $\left(\mathrm{m}^{7} \mathrm{G}\right)$ cap is hypermethylated by TGS1 (trimethylguanosine synthase 1) to form a 2,2,7-trimethylguanosine (TMG) cap. Generation of the TMG cap triggers assembly of the import complex, which includes the import adaptor snurportin (SPN) and the import receptor importin- $\beta$; both SPN and the SMN complex make functional contacts with importin- $\beta$ (for simplicity, other components of the SMN complex are not depicted). Upon nuclear re-entry, the Sm snRNPs transiently localize to Cajal bodies for nuclear maturation steps, followed by dissociation from SMN and storage within splicing factor compartments called nuclear speckles. Spliceosome assembly (detailed in Fig. 4) takes place at sites of pre-mRNA transcription. 


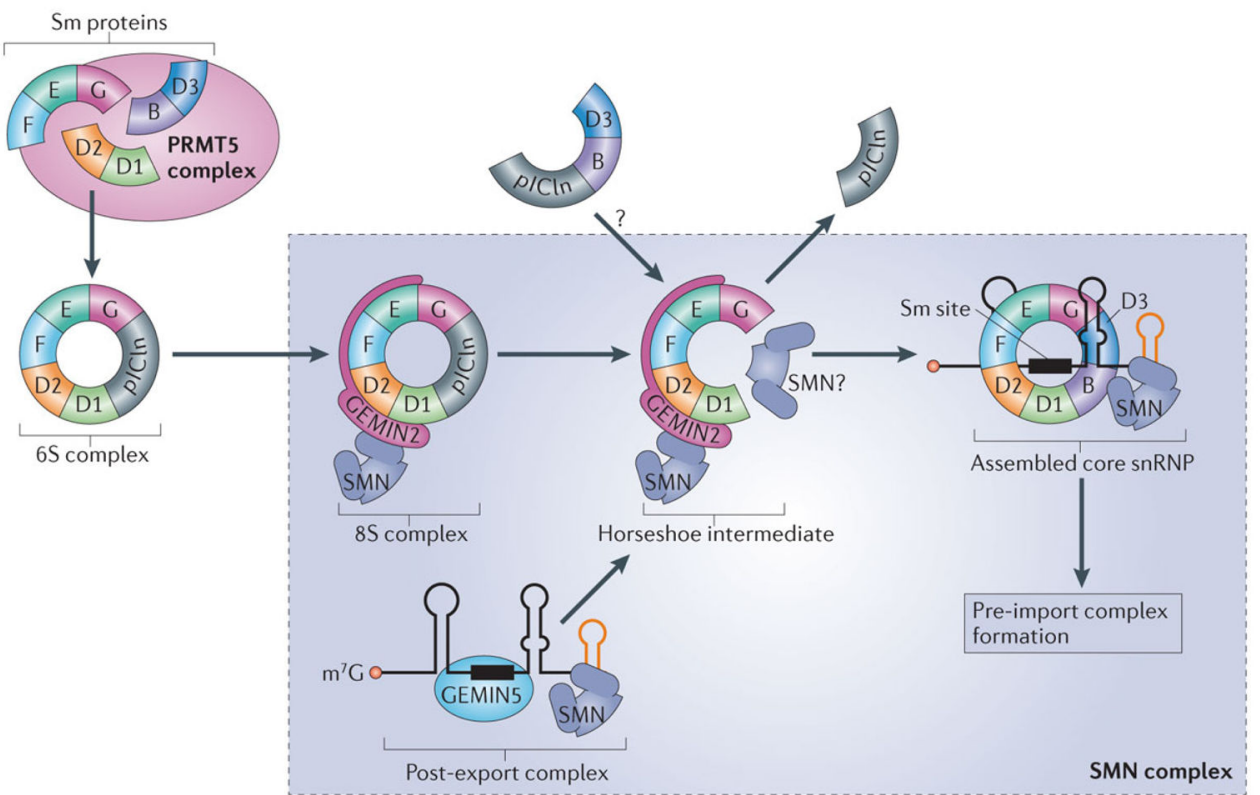

Figure 3. Assisted assembly of Sm-class snRNPs

Following their translation, Sm proteins are sequestered and symmetrically dimethylated by the PRMT5 complex. Once formed, the 6S complex of the Sm (D1-D2-F-E-G) pentamer and pICln is thought to be released from PRMT5c as a separate particle. This 6S complex is delivered to the oligomeric, multi-subunit SMN complex, which provides the overall platform for subsequent assembly steps. Gemin2, (Gem2), the heterodimeric binding partner of SMN, binds to the $6 \mathrm{~S}$ complex, forming an early $8 \mathrm{~S}$ assembly intermediate. In parallel, the SMN complex, including Gemin5 (Gem5), recognizes specific sequence elements (the Sm-site and the 3' stem-loop) within the post-export snRNA. A poorly understood series of rearrangements leads to formation of the assembled core snRNP. These involve recruitment of the $\mathrm{m}^{7} \mathrm{G}$-capped snRNA and the SmB-SmD3-pICln subcomplex, followed by dissociation of pICln. Prior to SmB-SmD3 incorporation, the 'horseshoe' intermediate may be stabilized by the Tudor domain of SMN, which contains an Sm fold. Incorporation of SmB-SmD3 and completion of the heteroheptameric ring requires the presence of an RNA that contains an Sm site. This produces an assembled core snRNP that is ready for downstream events including TMG capping and formation of the nuclear import complex (see Fig. 2). 

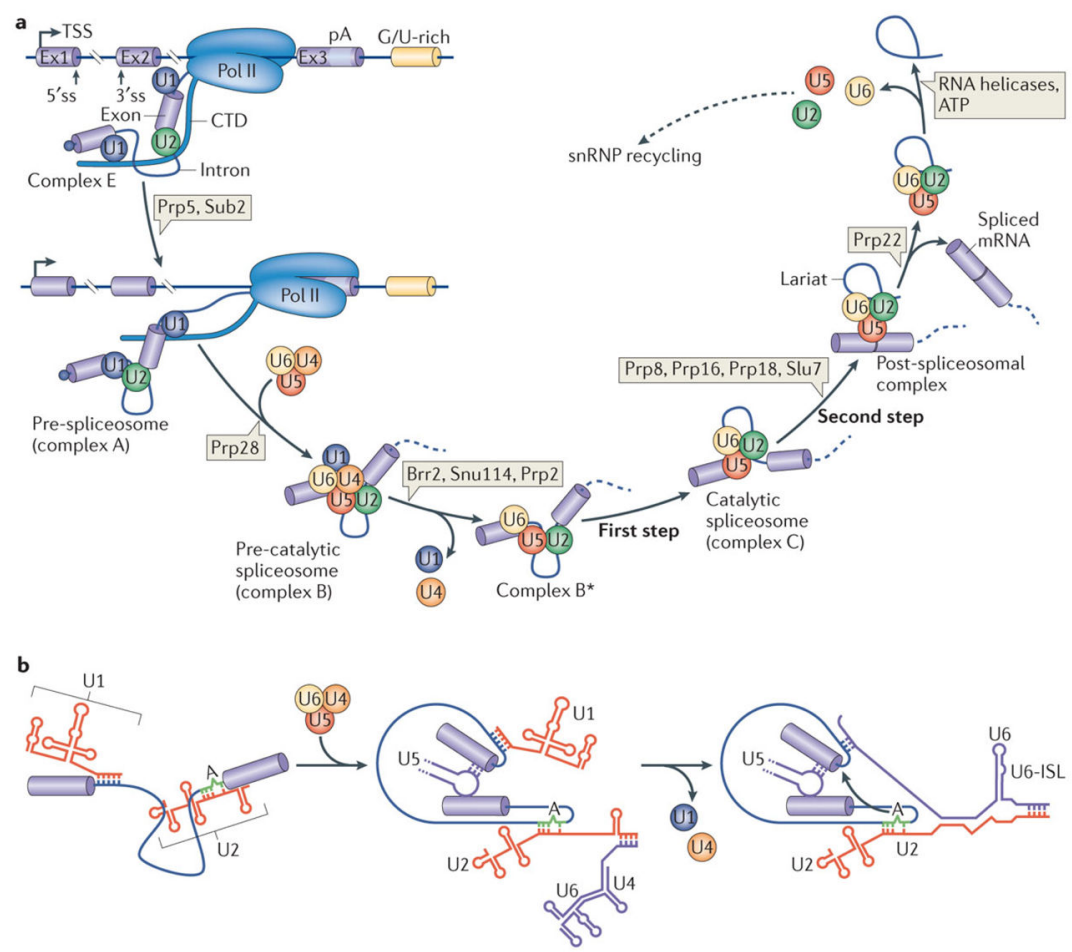

Figure 4. Step-wise assembly of the spliceosome and catalytic steps of splicing Spliceosome assembly takes place at sites of transcription. (a) The U1 and U2 snRNPs assemble onto the pre-mRNA in a co-transcriptional manner through recognition of the $5^{\prime}$ and $3^{\prime}$ splice sites, which is mediated by the C-terminal domain (CTD) of pol II. The U1 and U2 snRNPs interact with each other to form the pre-spliceosome (complex A). This process is dependent on $\mathrm{DExD} / \mathrm{H}$ helicases Prp5 and Sub2. In a subsequent reaction catalysed by Prp28, the preassembled tri-snRNP U4/U6•U5 is recruited to form complex B. The resulting complex B undergoes a series of rearrangements to form a catalytically active complex B (complex B*), which requires multiple RNA helicases (Brr2, Snu114 and Prp2) and results in the release of U4 and U1 snRNPs. Complex B* then carries out the first catalytic step of splicing, generating complex $\mathrm{C}$, which contains the free exon 1 and the intron-exon 2 lariat intermediate. Complex $\mathrm{C}$ undergoes additional rearrangements and then carries out the second catalytic step, resulting in a post-spliceosomal complex that contains the lariat intron and spliced exons. Finally, the U2, U5 and U6 snRNPs are released from the mRNP particle and recycled for additional rounds of splicing. Release of the spliced product from the spliceosome is catalysed by the DExD/H helicase Prp22 ${ }^{109,110}$. (b) During splicing, RNARNA interactions are rearranged in a stepwise manner to create the catalytic center of the spliceosome. Initially, U1 and U2 snRNA pair with the $5^{\prime}$ ss and the branch point sequence within complex A (left, the branch point adenosine is indicated). Subsequently, complex A associates with the U4/U6・U5 tri-snRNP, leading to new base pairs between U2 and U6 snRNA and between U5 snRNA and exonic sequences near the 5'ss (middle). The U4 snRNA is disassociated from U6 to expose the $5^{\prime}$ end of U6, which then base pairs with the 5 'ss to displace U1 snRNA (right). In the end, an extensive network of base pairing interactions is formed between $\mathrm{U} 6$ and $\mathrm{U} 2$, juxtaposing the 5 'ss and branch point adenosine 
for the first catalytic step of splicing. The central region of U6 snRNA forms an intramolecular stem-loop (the U6-ISL) that is key for splicing catalysis. 

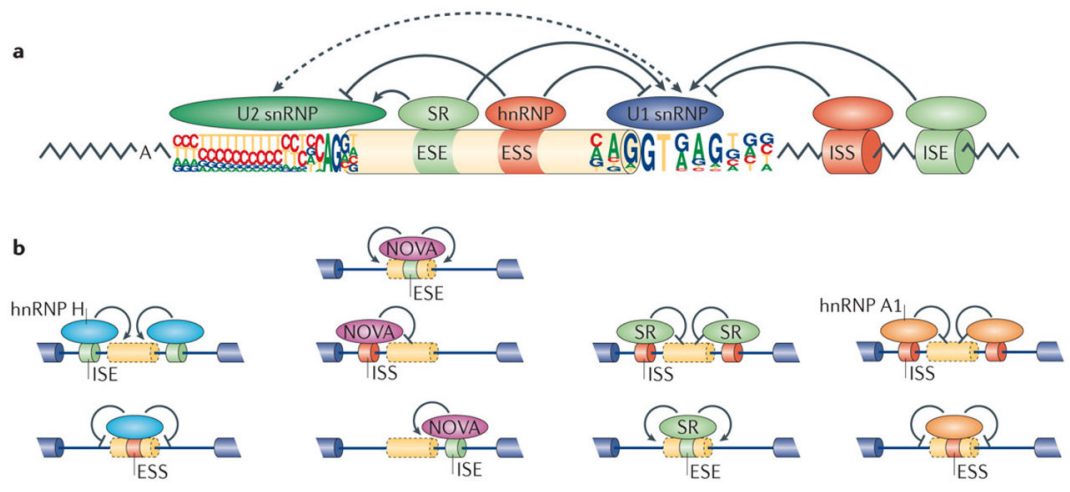

Figure 5. Regulation of alternative splicing

(a) Splice site choice is regulated through cis-acting splicing regulatory elements (SREs) and trans-acting splicing factors. Based on their relative locations and activities, SREs can be classified as exonic or intronic splicing enhancers and silencers (ESEs, ISEs, ESSs or ISSs). These SREs specifically recruit splicing factors to promote or inhibit recognition of nearby splice sites. Common splicing factors include SR proteins that recognize ESEs to promote splicing, as well as various hnRNPs that typically recognize ESSs to inhibit splicing. Both often affect the function of U2 and U1 snRNPs during spliceosomal assembly. (b) The activity of splicing factors and cis-acting SREs is context-dependent. Four well characterized examples are shown from left to right. Oligo-G tracts, recognized by hnRNP $\mathrm{H}$, function as ISEs to promote splicing when they are located inside an intron or as ESSs when located within exons (left). YCAY motifs, recognized by NOVA, act as ESEs when located inside an exon, as ISSs when located in the upstream intron of an alternative exon, or as ISEs when located in the downstream intron. Binding sites for SR proteins or hnRNP A1 also have distinct activities when located at different regions on the pre-mRNA. 
Table 1

Composition of major spliceosomal snRNPs*.

\begin{tabular}{|c|c|c|c|c|}
\hline snRNP & $\begin{array}{l}\text { RNA secondary structure } \\
\left.\text { (length }^{* * *}\right)\end{array}$ & Sm proteins & $\begin{array}{l}\text { Other core proteins } \\
\text { associated with snRNA }\end{array}$ & Associated proteins \\
\hline U1 snRNP & $\underset{(568 \mathrm{nt})}{\mathrm{C}}$ & $\begin{array}{l}\text { Sm proteins (B, D3, G, E, F, } \\
\text { D2 and D1) }\end{array}$ & $\begin{array}{l}\text { Snp1 (U1-70K) } \\
\text { Mud1 (U1A) } \\
\text { Yhc (U1C) }\end{array}$ & $\begin{array}{l}\text { Prp39, Prp40, Prp42 } \\
\text { Snu71 } \\
\text { Nam8 } \\
\text { Snu56 } \\
\text { Urn1 }\end{array}$ \\
\hline U2 snRNP & $\left\{\int_{(1175 \mathrm{nt})}\right.$ & $\begin{array}{l}\text { Sm proteins (B, D3, G, E, F, } \\
\text { D2 and D1) }\end{array}$ & $\begin{array}{l}\text { Lea1 (U2A'), Ms11 (U2B"), } \\
\text { Prp9 (SF3a60) } \\
\text { Prp11 (SF3a66) } \\
\text { Prp21 (SF3a120) } \\
\text { Rds3 (SF3b14b) } \\
\text { Snu17 (SF3b14a/p14) } \\
\text { Hsh155 (SF3b155) } \\
\text { Cus1 (SF3b145) } \\
\text { Rse1 (SF3b130) } \\
\text { Hsh49 (SF3b49) } \\
\text { Ysf3 (SF3b10) }\end{array}$ & $\begin{array}{l}\text { U2AF35 } \\
\text { Mud2 (U2AF65) } \\
\text { Ms15 (SF1/BBP) }\end{array}$ \\
\hline U4/U6 snRNP & (160/112 nt) & $\begin{array}{l}\text { Sm proteins for U4 snRNA } \\
\text { (B, D3, G, E, F, D2 and D1) } \\
\text { LSm proteins for U6 snRNA } \\
\text { (Lsm2-8) }\end{array}$ & $\begin{array}{l}\text { Prp3 } \\
\text { Prp31 } \\
\text { Prp4 } \\
\text { Snu13/15.5K }\end{array}$ & \\
\hline U5 snRNP & 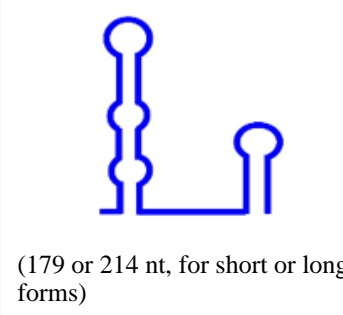 & $\begin{array}{l}\text { Sm proteins (B, D3, G, E, F, } \\
\text { D2 and D1) }\end{array}$ & $\begin{array}{l}\text { Prp8 } \\
\text { Prp6 } \\
\text { Prp28 } \\
\text { Brr2 } \\
\text { Snu114 } \\
\text { U5-40K } \\
\text { Dib1 }\end{array}$ & $\begin{array}{l}\text { Snu23 } \\
\text { Prp38 } \\
\text { Prp2 } \\
\text { Spp2 } \\
\text { Yju2 } \\
\text { Cbc2 (52K) }\end{array}$ \\
\hline U4/U5/U6 snRNP & $8 \longdiv { 5 }$ & $\begin{array}{l}2 \text { set of Sm proteins (B, D3, } \\
\text { G, E, F, D2 and D1) for U4 } \\
\text { and U5 } \\
1 \text { set of LSm proteins } \\
\text { (Lsm2-8) for U6 }\end{array}$ & $\begin{array}{l}\text { Prp3 } \\
\text { Prp31 } \\
\text { Prp4 } \\
\text { Snu13/15.5K } \\
\text { Prp8 } \\
\text { Prp6 } \\
\text { Prp28 } \\
\text { Brr2 } \\
\text { Snu114 } \\
\text { U5-40K } \\
\text { SnRNP27/27K } \\
\text { Dib1 }\end{array}$ & $\begin{array}{l}\text { Snu23 } \\
\text { Prp38 } \\
\text { Prp2 } \\
\text { Spp2 } \\
\text { Yju2 } \\
\text { Snu66 } \\
\text { Sad1 }\end{array}$ \\
\hline
\end{tabular}

Cus1, cold-sensitive U2 snRNA suppressor 1: Lea1, looks exceptionally like U2A 1; Lsm, Sm-like; Msl, Male-specific lethal homologue; nt, nucleotides; Prp, pre-mRNA processing; Rds3, regulator of drug sensitivity 3; Rse1, RNA splicing and ER to Golgi transport factor 1; Sad1, snRNP assembly-defective 1; SF, splicing factor; Spp2, suppressor of PRP; snRNA, small nuclear RNA; snRNP, small nuclear ribonucleoprotein; Snu, U5 small nuclear ribonucleoprotein component; U2AF, U2 auxiliary factor; Urn1, U2-U5-U6 snRNP, RES complex and NTC-interacting premRNA-splicing factor 1.

* The protein composition is primarily based on a mass spectrometric analysis of the yeast spliceosome ${ }^{174}$; certain regulatory factors that are closely associated with the core spliceosome (such as SR proteins) are not included. Proteins were listed using the budding yeast nomenclature unless there was no known yeast homologue. In certain cases, the common name of a metazoan homologue was also included.

**

The snRNA lengths are based on yeast transcripts. 